\title{
OPEN Biomechanical regulation of breast cancer metastasis and progression
}

\author{
Adrianne Spencer ${ }^{1,5}$, Andrew D. Sligar ${ }^{1,5}$, Daniel Chavarria ${ }^{1}$, Jason Lee ${ }^{1}$, Darshil Choksi ${ }^{1}$, \\ Nikita P. Patil ${ }^{1}$, HooWon Lee ${ }^{1}$, Austin P. Veith ${ }^{1}$, William J. Riley ${ }^{1}$, Shubh Desai ${ }^{1}$, \\ Ali Abbaspour ${ }^{1}$, Rohan Singeetham ${ }^{1}$ \& Aaron B. Baker ${ }^{1,2,3,4} \llbracket$
}

Physical activity has been consistently linked to decreased incidence of breast cancer and a substantial increase in the length of survival of patients with breast cancer. However, the understanding of how applied physical forces directly regulate breast cancer remains limited. We investigated the role of mechanical forces in altering the chemoresistance, proliferation and metastasis of breast cancer cells. We found that applied mechanical tension can dramatically alter gene expression in breast cancer cells, leading to decreased proliferation, increased resistance to chemotherapeutic treatment and enhanced adhesion to inflamed endothelial cells and collagen I under fluidic shear stress. A mechanistic analysis of the pathways involved in these effects supported a complex signaling network that included Abl1, Lck, Jak2 and PI3K to regulate pro-survival signaling and enhancement of adhesion under flow. Studies using mouse xenograft models demonstrated reduced proliferation of breast cancer cells with orthotopic implantation and increased metastasis to the skull when the cancer cells were treated with mechanical load. Using high throughput mechanobiological screens we identified pathways that could be targeted to reduce the effects of load on metastasis and found that the effects of mechanical load on bone colonization could be reduced through treatment with a PI3K $\gamma$ inhibitor.

Cancer cells are subjected to a complex mechanical microenvironment that includes extracellular matrix compliance, alterations in local mechanical stress due to tumor mass expansion, and applied force from interactions with surrounding organs and body motion. Biophysical forces are emerging as powerful regulators of cancer growth, quiescence and metastasis but our understanding of the mechanisms of the biomechanical regulation of tumor biology remains very limited ${ }^{1-3}$. While there is an increased appreciation of the role of tumor stiffness in regulating cancer biology $y^{4-6}$, the role of externally applied forces in the different stages of cancer progression is poorly understood. In normal breast tissues, there is a distribution of tension and compressive forces that are applied dynamically to the growing tumor mass ${ }^{7-9}$.

Several studies have also indicated that in rapidly growing tumors there is the development of compressive forces inside the tumor with tensional forces at the outer surface of growing tumor mass ${ }^{10}$. In prior studies, these compressive forces were found to increase the invasive phenotype of the cells ${ }^{10}$. Tensional forces are present in several regions of the growing cancer mass including the periphery of the tumor due to rapid tumor expansion, at the tumor/vasculature interface, and due to contraction of the skin/muscles during the motion of the body in exercise or daily activities ${ }^{8,11}$. Biomechanical models of the breast suggest that the tissues are subjected to cyclic forces with peaks of approximately 5-15 N around 5000 times per day from walking alone ${ }^{12}$. The elastic modulus of glandular tissue is estimate to range between 7.5 and $66 \mathrm{kPa}^{12}$. Thus, the breast is subjected to cyclic mechanical strains over a range from 1 to $25 \%$ strain during daily activity. Consequently, there are a rich variety of mechanical conditions within the breast tissue normally and these forces act on tumors that form within the tissue, potentially altering the course of the disease. Studies of the role of applied forces in regulating breast cancer support that compressive forces may enhance invasiveness ${ }^{10}$ but may also suppress proliferation ${ }^{13,14}$. However, the understanding of how applied mechanical forces alter breast cancer progression and metastasis remain poorly understood and therapies that can target these potentially powerful effects are lacking.

In this study, we examined the effects of applied mechanical tension on breast cancer metastasis, growth and chemoresistance. We found that mechanical tension causes widespread changes in gene expression in breast cancer cells, leading to increased expression of genes relating to cell adhesion, drug metabolism and activation

${ }^{1}$ Department of Biomedical Engineering, University of Texas at Austin, 1 University Station, BME 5.202D, C0800, Austin, TX 78712, USA. ${ }^{2}$ Institute for Cellular and Molecular Biology, University of Texas at Austin, Austin, TX, USA. Institute for Biomaterials, Drug Delivery and Regenerative Medicine, University of Texas at Austin, Austin, TX, USA. ${ }^{4}$ Institute for Computational Engineering and Sciences, University of Texas at Austin, Austin, TX, USA. ${ }^{5}$ These authors contributed equally: Adrianne Spencer and Andrew D. Sligar. ${ }^{\circledR}$ email: abbaker1@gmail.com 
of Yap signaling and a reduction in genes for proliferation. On a functional level, mechanical tension increases the ability of breast cancer cells to adhere to specific extracellular matrix (ECM) molecules and TNF- $\alpha$ activated endothelial cells. Moreover, we found that mechanical forces could slow the proliferation of breast cancer cells and increase their resistance to a broad range of chemotherapeutic agents. We performed a screen of compounds to inhibit the activation of the cancer cells by mechanical load and found several inhibitors that were able to block mechanical force-induced enhancement of cancer cell adhesion under flow. Finally, we show that mechanically conditioned breast cancer cells have enhanced metastasis, altered growth and increased chemoresistance. In addition, we performed mechanobiological screening to find compounds that inhibited mechanical enhancement of metastasis and demonstrated that these compounds were active in a mouse model of metastasis. Together our findings support that mechanical tension is a powerful regulator of multiple aspects of breast cancer biology.

\section{Materials and methods (Online)}

Cell culture. Human umbilical vein endothelial cells (HUVECs) were cultured in MCDB-131 growth medium supplemented with 5\% fetal bovine serum (FBS; Thermo Fisher Scientific, Inc.), SingleQuots growth supplements (Lonza), L-glutamine and penicillin/streptomycin. MDA-MB-231 and MCF-7 breast cancer cells were cultured in DMEM growth medium supplemented with $10 \%$ FBS, 1 X MEM Non-Essential Amino Acids, L-glutamine and penicillin/streptomycin. All cells were cultured at $37^{\circ} \mathrm{C}$ under a $5 \% \mathrm{CO}_{2}$ atmosphere.

High throughput cancer cell adhesion assay. In our past work, we developed a high throughput system for applying flow to cells cultured in 96 well plates ${ }^{15-17}$. The device is composed of a rotational motor that drives a 96 gear box, simultaneously rotating 96 shafts with low angle cone tips, which interface with a standard format 96 well plate. As the low angle cones are brought into close proximity with the bottom of the wells, a linear shear stress is applied to the area of the well under the rotating cones. The high throughput cancer cell adhesion assay is performed by culturing HUVECs to confluence and then treating them with $10 \mathrm{ng} / \mathrm{ml} \mathrm{TNF-} \alpha$ for four hours prior to the adhesion assay. Cancer cells were labeled with CellTracker Dye (Thermo Scientific) for 45 min, trypsinized to detach them from the plate, and then allowed to recover in suspension for one hour prior to the start of the adhesion assay. We then added $1 \times 10^{5}$ fluorescently labeled cancer cells/well to the well plate and applied 0.5 dynes $/ \mathrm{cm}^{2}$ of shear stress for one hour. Non-adherent cells were washed from the well plate with PBS and remaining adherent cancer cells were detected using a plate reader. To assess the strength of adhesion of the adherent cancer cells, increasing bouts of shear stress were applied. Shear stresses of 1, 2, 3, 4, 5, 10 and 20 dynes/ $\mathrm{cm}^{2}$ were applied for one minute increments, detached cells were washed from the plate, and the fluorescence of the remaining adherent cells were read by fluorescent plate reader after each level of shear stress.

High throughput device for applying mechanical stretch to cultured cells. Our group has previously created a high throughput device that applies mechanical stretch to cancer cells in a $6 \times 96$ well format ${ }^{18-21}$. Cells were cultured on custom 96-well culture plates with a flexible silicone membrane culture surface. Custom cell culture plates were assembled by sandwiching the silicone membrane between silicone gaskets, which were supported by polycarbonate wells and an aluminum base plate. The culture membrane was made of medical grade gloss/gloss $0.005^{\prime \prime}$ thick silicone. The well plates were sterilized by UV light and coated with collagen I $(110 \mu \mathrm{g} / \mathrm{mL})$ overnight. The well plates were mounted onto the stretch device and a true linear motor was used to drive platen with mounted pistons. Polytetrafluoroethylene pistons (5-mm diameter) on the platen were individually calibrated to apply precise amounts of equibiaxial strain to the silicone membrane. As the pistons are driven upward into the flexible membrane, the membrane is displaced a programmable distance which directly correlates to the application of a percent strain. The platen is mounted with linear ball bearings that run on six motion rails to guide precise alignment and motion of the platen. Vegetable oil was used to lubricate the pistons in contact with the silicone membrane of the culture plates.

Adhesion assays following mechanical loading. Silicone membrane bottom plates were coated with collagen I $(110 \mu \mathrm{g} / \mathrm{mL})$ overnight. Cancer cells were seeded at a concentration of $1 \times 10^{5} \mathrm{cells} / \mathrm{mL}$ for $24 \mathrm{~h}$ prior to application of strain. Cells were either cyclically strained at 0.1 or $1 \mathrm{~Hz}$ for $24 \mathrm{~h}$. Cancer cells were then trypsinized and allowed to recover for $1 \mathrm{~h}$ in suspension. The suspension of cancer cells was added to a 96 well plate with confluent TNF- $\alpha$ activated HUVECs or purified extracellular matrix components fibronectin, collagen I, collagen II, collagen IV, vitronectin or laminin, and then adhesion and detachment assays were performed, as described above.

Integrin and kinase inhibitor library treatment. MDA-MB-231 breast cancer cells were cultured on flexible membrane well plates, then treated with integrin inhibitors or kinase inhibitors for one hour before inducing cyclic mechanical strain. The integrin inhibitors used are listed in Supplemental Table S1. The kinase inhibitor library (EMD Calbiochem; Cat. No. 539744) was used at a concentration of $10 \mu \mathrm{M}$ for each inhibitor. After the addition of either integrin inhibitors or the kinase inhibitor library, cancer cells were mechanically strained for $24 \mathrm{~h}$. After mechanical strain, the cancer cells were detached from the well plate in trypsin for $2 \mathrm{~min}$, spun down at $500 \mathrm{~g}$, resuspended and allowed to recover for $60 \mathrm{~min}$ in suspension. The cells were then used in the adhesion-detachment assays as described above.

Immunostaining. After application of cyclic strain for $24 \mathrm{~h}$, the cells were washed with PBS and then fixed in $4 \%$ paraformaldehyde for $10 \mathrm{~min}$. The membranes were cut into strips and mounted onto glass slides for staining. The cells were permeablilized in $0.2 \%$ Triton X-100 in PBS for 5 min and then blocked with $5 \%$ FBS in 
PBS and $1 \%$ BSA for 45 min. The cells were labeled with a 1:100 or 1:50 primary antibody dilution in PBS with $1 \%$ BSA overnight at $4{ }^{\circ} \mathrm{C}$. Cells were washed with PBS with $1 \%$ BSA, and labeled with fluorescent secondary antibodies and DAPI at a 1:1000 dilution (from a stock of $1 \mathrm{mg} / \mathrm{ml}$ ) for $75 \mathrm{~min}$ at room temperature in the dark. The cells were washed extensively with PBS and mounted in mounting media (Vector Labs). The antibodies used in the studies are listed in Supplemental Table S2. For the studies with drug treatment and immunostaining the following inhibitors were used: Akt Inhibitor VIII (CAS 612847-09-3), JAK3 Inhibitor II (CAS 211555-04-3), JAK3 Inhibitor VI (CAS 856436-16-3), Lck Inhibitor (CAS 213743-31-8), PDGFR Tyrosine Kinase Inhibitor V (CAS 347155-76-4), N-Benzoyl Staurosporine (CAS 120685-11-2), PI3K $\gamma$ inhibitor (CAS 648450-29-7) and Verteporfin (CAS 129497-78-5).

Western blot analysis. The cells were treated with the inhibitors described in the immunostaining experiments or on of the following inhibitors: Asciminib (CAS 1492952-76-7), Radotinib (CAS 926037-48-1), AZD1480 (CAS 935666-88-9), or Ruxolitinib (CAS 941678-49-5). Following treatments, the cells were washed with PBS and lysed using the following lysis buffer: $20 \mathrm{mM}$ Tris $(\mathrm{pH}=8.0), 5 \mathrm{mM}$ EDTA, $150 \mathrm{mM} \mathrm{NaCl}, 1 \%$ Triton-X 100, $0.1 \%$ sodium dodecyl sulfate, $2 \mathrm{mM}$ activated sodium orthovanadate, $1 \mathrm{mM}$ phenylmethyl sulfonyl fluoride, $50 \mathrm{mM} \mathrm{NaF}$, and a protease/phosphatase inhibitor cocktail (Thermo Scientific). Lysis buffer was added to the wells for $10 \mathrm{~min}$, followed by scraping with cell scrapers. Lysate was alternately sonicated for $1 \mathrm{~min}$ and kept on ice for $5 \mathrm{~min}$ for three cycles. The lysate was then centrifuged for $10 \mathrm{~min}$ at 10,000 g. A protein assay was used to normalize the total protein in the samples (BCA assay; Thermo Scientific). The samples were mixed with 4X LDS Sample buffer in a 3:1 ratio with 5\% $\beta$-mercaptoethanol. Samples were run on a precast NuPAGE Novex 4-12\% Bis-Tris gels and transferred with iBlot transfer stacks to nitrocellulose membranes. The membranes were blocked in 5\% milk in TBST or 5\% StartingBlock T20 (Thermo Scientific) in TBST for one hour at room temperature. The membranes were then incubated in $1^{\circ}$ antibody in $1 \%$ milk or $1 \%$ StartingBlock T20 in TBST at $4{ }^{\circ} \mathrm{C}$ overnight. Then the membrane was washed in TBST and incubated in $2^{\circ}$ antibody (HRP conjugated) in $1 \%$ milk or $1 \%$ StartingBlock T20 in TBST at room temperature for $2 \mathrm{~h}$. The antibodies used in the studies are listed in Supplemental Table S3. The membrane was washed extensively in TBST. The membranes were treated with luminol solution (SuperSignal West Femto Maximum Sensitivity Substrate; Thermo Fisher Scientific, Inc.) and then imaged using chemiluminescence imager (GBox-F3; Syngen Biotech.).

RNA sequencing and analysis. MDA-MB-231 breast cancer cells were treated with mechanical loading for $24 \mathrm{~h}$ and then RNA was isolated using the Qiagen RNeasy Mini Kit. The mRNA was sequenced using an Illumina HiSeq 4000. Single reads of 50 base pairs were performed after poly-A mRNA capture (Ambion Poly(A) Tailing Kit and NEBNext Ultra II Directional RNA Library Prep Kit) to isolate mRNA and dUTP directional preparation of the mRNA library. RNA sequencing was performed by the Genomic Sequencing and Analysis Facility at UT Austin. Gene expression analysis was performed using DESeq2 and R software ${ }^{22}$. Data processing and analysis was as described previously ${ }^{23}$. Plots were created using Prism GraphPad and Microsoft Excel. Gene ontology was performed using LAGO (Lewis-Sigler Institute, Princeton).

Effect of mechanical strain on chemotherapeutic drug response. MDA-MB-231 cells were plated on collagen I coated, custom made 96 well plates with flexible silicone bottoms. Cyclic mechanical strain at 7.5\% or $15 \%$ was applied or cells were cultured statically for $8 \mathrm{~h}$. The cells were then dosed with paclitaxel, doxorubicin or 5-fluorouracil over a range of concentrations. Cells were strained for $16 \mathrm{~h}$ followed by a second dose, and then an additional $24 \mathrm{~h}$ of strain. At the conclusion of the assay, the cells were fixed with $4 \%$ paraformaldehyde, and the number of cells per field of view was quantified using DAPI staining.

Multi drug resistance flow cytometry assay. MDA-MB-231 breast cancer cells were mechanically strained at $0 \%$ and $7.5 \%$ strain for $24 \mathrm{~h}$. The EFLUXX-ID Gold multi drug resistance assay kit (Enzo Life Science) was used. For each sample, $5 \times 10^{5}$ cells were treated with multi drug resistance inhibitors or untreated for $5 \mathrm{~min}$, and then the Gold Efflux dye was added to all cells for $30 \mathrm{~min}$. Propidium iodide was used to monitor cell viability. Cell fluorescence was then quantified via flow cytometry. Flow cytometry was performed using a LSRII Fortessa flow cytometer (BD Biosciences). FlowJo software (FlowJo, LLC) was used to analyze the results of the flow cytometry.

Flow cytometry analysis of cell adhesion markers. MDA-MB-231 breast cancer cells were mechanically strained at $0 \%$ and $7.5 \%$ cyclic mechanical strain for $24 \mathrm{~h}$. Following application of stretch, cancer cells were washed with PBS and detached from the flexible membrane using a cell scraper. The cells were centrifuged at $650 \mathrm{~g}$ for $6 \mathrm{~min}$ and washed in cold BD Stain Buffer, then $1 \times 10^{6}$ cells were labeled with fluorescently conjugated antibodies for $30 \mathrm{~min}$ at $4{ }^{\circ} \mathrm{C}$. The antibodies used are listed in Supplemental Table S2. Cells were washed twice in $1 \mathrm{~mL}$ of Stain Buffer. Cells were then fixed in $1 \%$ paraformaldehyde for $30 \mathrm{~min}$ at $4{ }^{\circ} \mathrm{C}$, then washed and stored in Stain Buffer until flow cytometry. Flow cytometry was performed using a LSRII Fortessa flow cytometer (BD Biosciences). FlowJo software (FlowJo, LLC) was used to analyze the results of the flow cytometry.

Tube formation assay. Cancer cells were grown under static or mechanically loaded conditions for $24 \mathrm{~h}$. Cancer cells and HUVECs were labeled using CellTracker dye (Thermo Scientific) following the manufacturer's instructions. HUVECs were seeded onto Matrigel in a glass bottom 96-well plate at a concentration of 20,000 cells per well. The HUVECs were treated with conditioned media from cancer cells by diluting the conditioned media in endothelial growth media in a 1:1 dilution. Cancer cells were seeded onto Matrigel at 20,000 cells per 
well into glass bottom 96-well plates. The formation of tubes in both assays was imaged using a Cytation 5 Cell Imaging Multi-Mode Reader (BioTek).

Mouse xenograft model of metastasis. Luciferase expressing MDA-MB-231 cells were purchased from Perkin Elmer, Inc. NOD/Scid mice (001303; Jackson Laboratory, Inc.) or nu/nu mice (002019; Jackson Laboratory, Inc.) were used in this study. For the xenograft study of breast cancer metastasis, MDA-MB-231 breast cancer cells were exposed to mechanical strain or static conditions for $24 \mathrm{~h}$. The cancer cells were either untreated or, treated with $10 \mu \mathrm{M}$ of PI3-K $\gamma$ inhibitor (CAS 648450-29-7). We injected $5 \times 10^{5}$ cells were injected into the tail vein of 7-week-old female mice. The mice were given an intraperitoneal injection of luciferin $(150 \mathrm{mg} / \mathrm{kg})$ in DPBS 10 min prior to imaging. The luminescence was visualized using the Xenogen IVIS Spectrum In Vivo Imaging System (PerkinElmer).

Mouse orthotopic xenograft model. $\mathrm{Nu} / \mathrm{Nu}$ mice (002019; Jackson Laboratory, Inc) were used in this study. For the xenograft study, luciferase-expressing MDA-MB-231 breast cancer cells were conditioned with mechanical strain or static conditions for $12 \mathrm{~h}$ a day for 7 days. Following mechanical conditioning, $1 \times 10^{6}$ cells were injected in $100 \mu \mathrm{l}$ of Matrigel (Corning) into the inguinal mammary fat pad. Tumors were monitored daily and tumor growth was recorded with caliper measurements every other day. A laser speckle contrast imager (LSCI) was used in the orthotopic model to non-invasively quantify blood perfusion in the area of the injection. Imaging was performed as previously described with the entire back of the mouse captured in one image $e^{24,25}$. The back of the mouse was illuminated with a diffuse laser diode (Thor Labs, $785 \mathrm{~nm}, 50 \mathrm{~mW}$ ) to create a speckle pattern. The speckle pattern was captured using a Zoom-700 lens (Navitar) with a Bassler CCD (Graftek) and quantification was done using the contralateral side of the back as a relative control. To ensure comparability, both regions were captured simultaneously in one image. All animal procedures were approved by the Institutional Animal Care and Use Committee of UT Austin and were performed in accordance with the Guide for the Care and Use of Laboratory Animals published by the National Institutes of Health and Animal Research: Reporting of In Vivo Experiments (ARRIVE) guidelines.

Micro-CT analysis. The mice were imaged using micro-CT in the High Resolution X-Ray CT Facility at the University of Texas at Austin. The mice were perfusion fixed and then scanned using a micro-CT imaging system consisting of an NSI scanner, a Fein Focus High Power source, aluminum filter, and a Perkin Elmer detector. The scan was conducted at $140 \mathrm{kV}$, a source to object distance of $283 \mathrm{~mm}$ a source to detector distance of $1180 \mathrm{~mm}$, and $0.25 \mathrm{pF}$ gain. The scan was continuous with 2 frame averaging, 1800 projections, 5 gain calibrations, $5 \mathrm{~mm}$ calibration phantoms and a 0.1 beam-hardening correction. Post reconstruction ring correction was applied using $2 \times$ over sampling, a radial bin width of 21 pixels, 32 sectors, a minimum arch length of 8 pixels, angular bin width of 9 pixels, angular screening factor of 4 , and a voxel size of $51.5 \mu \mathrm{m}$. The raw CT slices were reconstructed using VGStudio 2.1, isolating the skull and preforming background subtraction. Light intensity and camera height were kept constant.

Statistical analysis. All results are shown as mean \pm S.E.M., unless otherwise specified. Comparisons between multiple groups were analyzed using a two-way analysis of variance followed by a Tukey post hoc test. For studies that did not have normally distributed data, a Kruskal-Wallis test followed by multiple comparisons using the Conway-Imam procedure. Comparisons between only two groups with normally distributed data were analyzed using a Student's $t$ test. A two-tailed probability value $p<0.05$ was considered statistically significant. Unless otherwise indicated, all statistical analyses were done in Prism GraphPad (version 8) or Microsoft Excel with XLSTAT (version 2015.4.01.21576).

\footnotetext{
Results

Mechanical stretch dramatically alters gene expression profiles in breast cancer cells, including gene sets associated with Yap and Zeb transcription factors. We treated MDA-MB-231 cancer cells with mechanical strain (no strain, $7.5 \%$, or $15 \%$ strain at $1 \mathrm{~Hz}$ ) for $24 \mathrm{~h}$ and then examined the change in gene expression using RNAseq. Mechanical loading at both magnitudes led to a broad shift in gene expression (Fig. 1A,B; Supplemental Fig. S1). Gene ontology of the significantly regulated genes identified significant upregulation in gene sets relating drug metabolism processes, angiogenesis, and regulation of proliferation and migration for cells treated with $7.5 \%$ strain (Fig. 1C). The most significantly altered gene sets were relating to fatty acid metabolism and other metabolism related gene sets for cells treated with $7.5 \%$ strain. At $15 \%$ strain, the most altered gene sets related to cellular differentiation, signaling and cell adhesion while the most downregulated genes were involved in morphogenesis, blood vessel development and epithelial branching (Fig. 1D). Several genes associated with drug metabolism were also among the most upregulated genes in the entire genome, including Aldo-Keto Reductase Family 1 Member C1 (AKR1C1) that had a greater than 20 -fold increase compared to static cultured cells (Supplemental Fig. S1B). We also observed large increases in related also-keto reductases AKR1B1 and AKR1B10. In addition, we found a decrease in expression of genes associated with proliferation compared to statically cultured cells (Supplemental Fig. S1C). Many genes known to be controlled by Yap and Zeb transcription factors were also significantly regulated at both $7.5 \%$ and $15 \%$ strain compared to static cells (Supplemental Fig. S1D). In addition, there was a significant shift in expression for genes relating to cell-cell adhesion and cell adhesion to extracellular matrix (Supplemental Fig. S1E).
} 
A

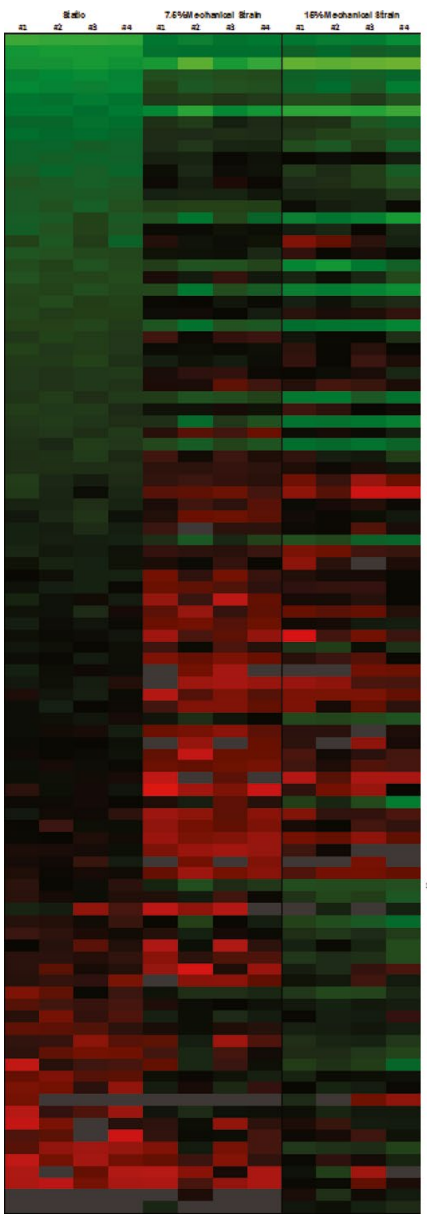

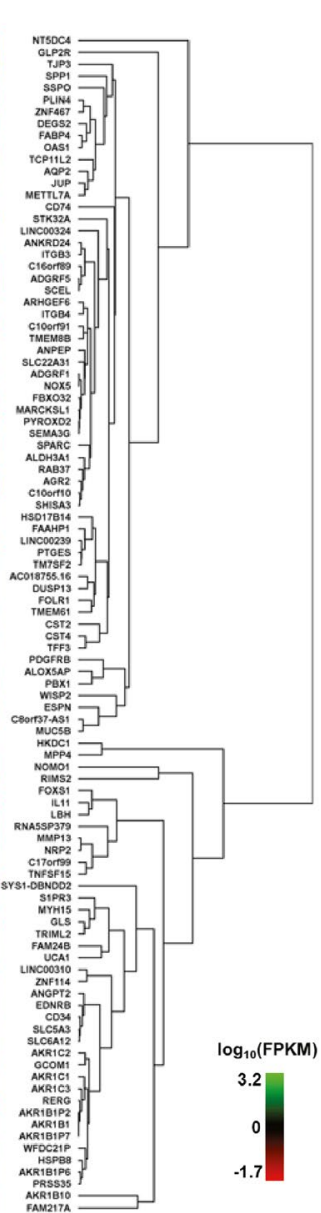

B Positively Regulated Genes $7.5 \%$ Strain $15 \%$ Strain

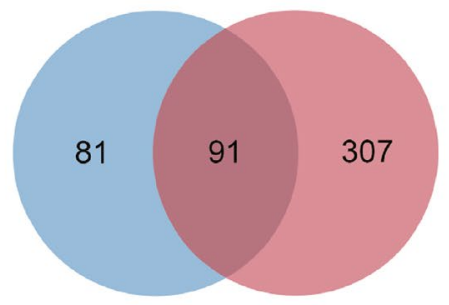

C

Daunorubicin/Doxorubicin Met. Process Positive Regulation of Angiogenesis Cell Proliferation

Amino Acid Transmembrane Transport Cell Migration Small Molecule Metabolic Process Response to Nutrient Levels Response to External Stimulus Fatty Acid Metabolic Process Lipid Metabolic Process

D

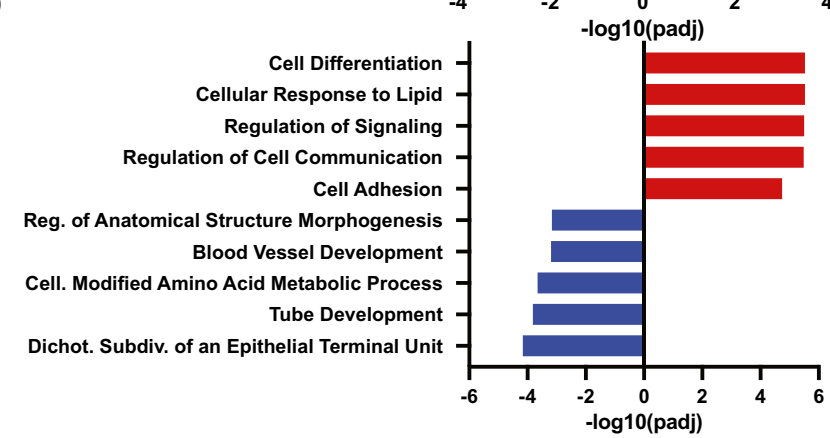

Figure 1. Mechanical strain regulates gene transcription of cell adhesion, drug metabolism and proliferation genes. MDA-MB-231 breast cancer cells were treated with mechanical strain for $24 \mathrm{~h}$ at $0,7.5$, and $15 \%$ maximal strain at a frequency of $1 \mathrm{~Hz}$. Total RNA was isolated and RNA sequencing was performed $(\mathrm{n}=4)$. $($ A) Hierarchical clustering of the most significantly regulated genes. FPKM = fragments per kilobase of transcript per million mapped reads. (B) Venn diagrams for significantly regulated genes in the $7.5 \%$ and $15 \%$ mechanical strain groups. (C) The top five most upregulated and downregulated gene ontology groups for cells treated with $7.5 \%$ strain. (D) The top five most upregulated and downregulated gene ontology groups for cells treated with $15 \%$ strain. R software was used to create parts of this figure ${ }^{22}$.

Mechanical strain decreases proliferation and apoptosis signaling and increases breast cancer resistance to chemotherapeutic drugs. Using a high throughput mechanical loading system recently developed by our laboratory, we conditioned cancer cells with a physiological range of mechanical strains ranging from 0 to $17.5 \%$ strain to MDA-MB-231 breast cancer cells. Overall metabolic activity as measured by an MTT assay was over $50 \%$ lower in cells under $7.5 \%$ mechanical strain in comparison to cells grown under static conditions (Supplemental Fig. S2). Immunostaining for anti-apoptotic Bcl-2 and pro-apoptotic Bax showed a reduction in the ratio between $\mathrm{Bax}$ and $\mathrm{Bcl}-2$ with mid-range mechanical strains (Fig. 2A,B). Gene expression for Bax and Bcl-2 RNAseq was consistent with these findings, showing increases in both the Bax and BCL2 genes however there was no alteration in the ratio of Bax to BCL2 in gene expression (Fig. 2C). To examine, the effect of extracellular forces can alter chemoresistance, we applied chemotherapeutic compounds to the cells in combination with $7.5 \%$ or $15 \%$ cyclic mechanical strain. We found mechanically loaded cells had reduced proliferation however there was little alteration in the proliferation of loaded cells even in the presence of high doses of paclitaxel, doxorubicin, and 5-fluorouracil (Fig. 2D). We repeated these studies on MCF7 cells and found that mechanical load reduced the proliferation of the cells and made them insensitive to doxorubicin treatment (Supplemental Fig. S3). A multidrug resistance assay showed that mechanical conditioning at $7.5 \%$ strain did not affect MDR1, MRP1/2 and BCRP drug efflux pump activity (Supplemental Fig. S4).

In previous studies, alterations in the Abll signaling in breast cancer cells led to increased chemoresistance while reducing proliferation ${ }^{26,27}$. Abl1 is also associated with the cytoskeleton and is mechanically regulated in other cell types ${ }^{28,29}$. We applied $7.5 \%$ mechanical strain to the cells with or without inhibitors to Abl1, Jak2 or PI3K and then performed immunoblotting to cell survival and signaling pathways (Fig. 2E,F; Supplemental Figs. S5-S8). Mechanical loading led to increases in phosphorylated Bcl-xL, p-p70/85 S6K, Akt, Jak2, PI3K, and $\mathrm{Mcl} 1$. In addition, there were increases in total p70 S6K and a reduction in cyclin D1. Inhibitors to Abl1 
A
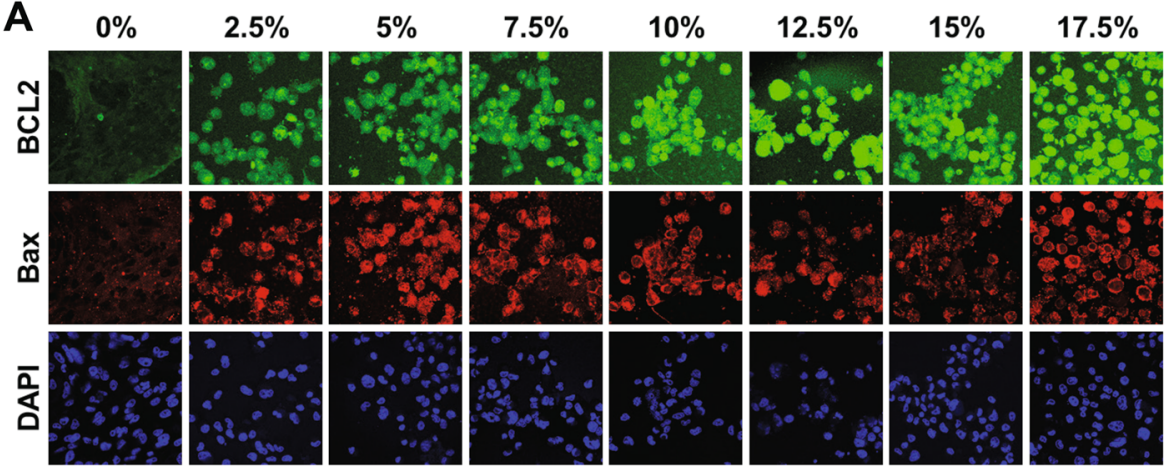

B
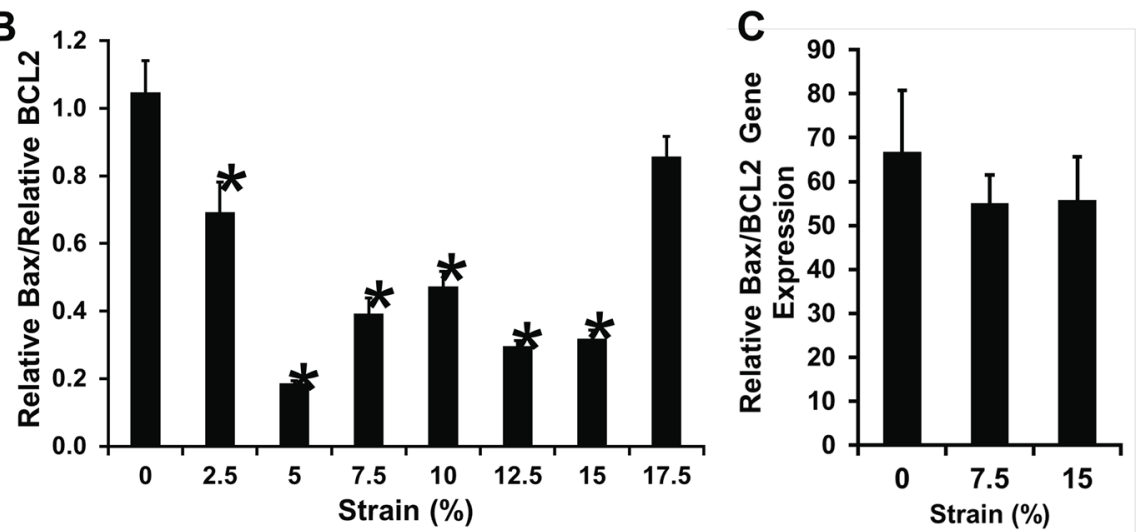

D

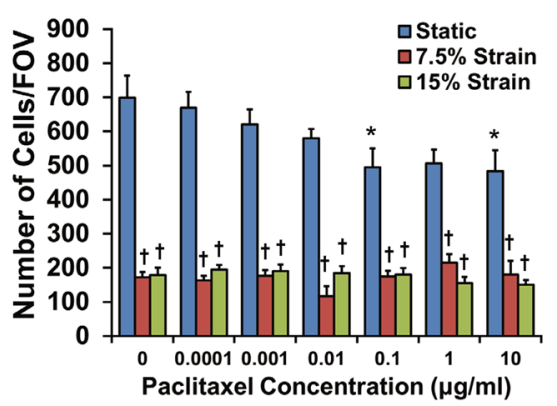

Doxorubicin

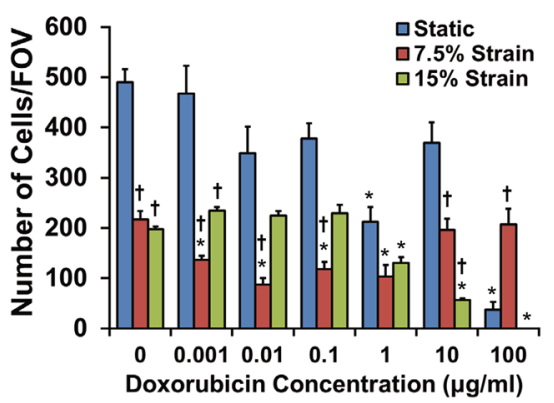

E
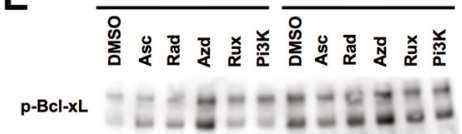

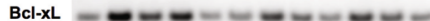

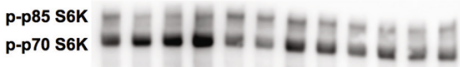

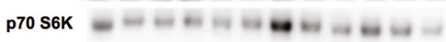

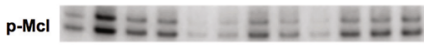

Mcl

GAPDH =

F

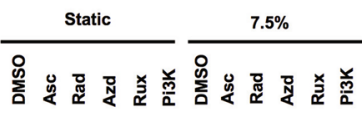

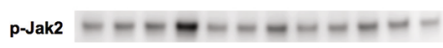

Jak2 $=--\cdots---\cdots--1-$

p-Stat5 ーーーーーーーーーーーー

Stat5 - ーーーーーーーーーーー

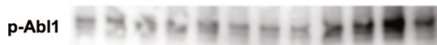

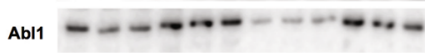

p-Akt $=-m=-2=0$

Akt $=00-0=-0$

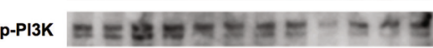

PI3K $-ー-ー-\cdots+-\cdots-\cdots$

\section{5-Fluorouracil}

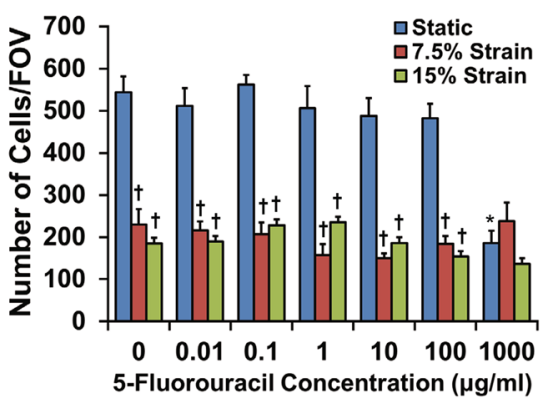

Figure 2. Mechanical strain decreases proliferation and increases drug resistance in breast cancer cells. (A) Images of Bax and Bcl-2 immunostaining for cyclic mechanical strains of $0-17.5 \%$ strain. Bar $=100 \mu \mathrm{m}$. (B) Relative expression of pro-apoptotic Bax to anti-apoptotic Bcl-2 protein expression. ${ }^{\star} p<0.05$ versus $0 \%$ strain $(n=10)$. (C) Relative gene expression of Bax to Bcl-2 after $24 \mathrm{~h}$ of mechanical strain $(n=10)$. (D) Response of MDA-MB-231 breast cancer cells to drug treatment with paclitaxel, doxorubicin, or 5 -fluorouracil under $0 \%$, $7.5 \%$, or $15 \%$ mechanical strain $(n=8) .{ }^{*} p<0.05$ versus static conditions. ${ }^{\dagger} p<0.05$ versus static conditions under no treatment and under static conditions with the pharmacological treatment with same concentration as the indicated group. (E) Western blotting for cells treated with 7.5\% strain in combination with DMSO, asciminib (Asc; Abl1 inhibitor), radotinib (Rad; c-Abl1 inhibitor), AZD1480 (Azd; Jak2 inhibitor), Ruxolitinib (Rux; Jak1/2 inhibitor), or a PI3K inhibitor (PI3K). (F) Western blotting for cells treated with $7.5 \%$ strain and the indicated inhibitors. Full-length blots/gels are presented in Supplemental Figs. S6-S7.

reduced the load-induced phosphorylation of Bcl-xL, PI3K and Mcl1 while inhibitors to Jak2 or PI3K reduced load-induced phosphorylation of Akt (Fig. 2E,F; Supplemental Figs. S5-S6). Together, these findings suggest a load activated signaling pathway in which Abl1 and Jak2 are activated by mechanical load to induce increases in pro-survival signaling (Supplemental Fig. S9).

Mechanical strain increases adhesion of breast cancer cells to endothelial cells and collagen I. A key step during metastasis is the adhesion and arrest of circulating cancer cells to the endothelium or subendothelial matrix ${ }^{30,31}$. Using the high throughput mechanical loading system, we applied mechanical stretch to MDA-MB-231 breast cancer cells over a range from 0 to $17.5 \%$ maximal strain for $24 \mathrm{~h}$. Our group has developed a high throughput flow system that allows the application of controlled flow in a 96 well plate format ${ }^{15,17,32}$. 
The system uses low angle cones rotated near the culture surface of the well to produce shear on the cells. We performed assays for cell adhesion under flow using the high throughput flow system after applying mechanical load (Fig. 3A). After initial adhesion under flow, we washed the plates and then applied progressively increasing shear stress in short bouts to detach the cells and assess the strength of adhesion. We found that all levels of strain tested increased adhesion to endothelial cells pretreated with TNF- $\alpha$ (Fig. 3B). There were no significant changes in the strength of adhesion for the strained cells (Fig. 3C). To test the specificity of adhesion induced by mechanical loading we repeated the experiment exposing the cells to $5 \%$ strain for $24 \mathrm{~h}$ and then tested adhesion to non-TNF- $\alpha$ treated endothelial cells and purified ECM molecules. We found that there was increased initial adhesion to TNF- $\alpha$ treated endothelial cells and to collagen I but not to other ECM molecules or non-inflamed endothelial cells (Fig. 3D). There was an increase in the strength of adhesion of cells to collagen I but not to other ECM molecules or endothelial cells (Fig. 3E). We also repeated the studies in MCF-7 cells and found that there was an increase in adhesion with loading to endothelial cells (with or without TNF- $\alpha$ ), fibronectin, and collagen IV (Supplemental Fig. S10). We next repeated the studies and included the treatment with integrin and focal adhesion kinase (FAK) inhibitors shown in Supplemental Table S1 during the mechanical strain (but not during the adhesion assay). Inhibitors to $\beta 1$ integrins, $\alpha v \beta 3 / \beta 5$ integrins, pan-integrin inhibitor and the FAK inhibitor, reduced the mechanical strain strain-enhanced cell adhesion and adhesion strength to endothelial cells (Fig. 3F,G). In addition, we repeated our loading studies on the cells with a range of mechanical loads and found increased actin stress fiber formation with strains from 7.5 to $12.5 \%$ maximal strain, consistent with enhanced adhesion with these treatments (Supplemental Fig. S11).

High throughput mechanobiological screen identifies kinase inhibitors that inhibit mechanical strain enhanced cancer cell adhesion to inflamed endothelial cells. We next performed a high throughput screen to identify potential pathways and compounds that could be used to inhibit the load-induced enhancement of cancer cell to endothelial cell adhesion under flow. We treated cancer cells with mechanical load at $7.5 \%$ strain at $1 \mathrm{~Hz}$ under treatment with compounds from a drug library of kinase inhibitors. After $24 \mathrm{~h}$, we performed a cell adhesion assay under shear stress using the high throughput flow system to identify compounds that decreased cancer cell adhesion under both static and mechanical loading conditions (Fig. 4A). The screen allowed an assessment of initial adhesion as well as an index for strength of adhesion by calculating a shear stress at which $50 \%$ of the cells would be removed $\left(\tau_{50}\right.$; Fig. 4B-D). Inhibitors for EGFR reduced adhesion of cells cultured statically ( 10 of 12 inhibitors) and under mechanical load (5 of 12 inhibitors). Under static conditions, inhibitors for FLT-3 ( 3 of 3 inhibitors) and PDGFR ( 6 of 9 inhibitors) reduced adhesion but not for cells treated with mechanical load. Inhibitors for JAK3 ( 2 of 3 inhibitors), PI3K ( 2 of 4 inhibitors), Syk (2 of 3 inhibitors) and VEGFR ( 3 of 6 inhibitors) reduced adhesion to varying degrees in cells cultured under static or mechanical loading conditions. For inhibiting adhesion strength, inhibitors of AKT ( 3 of 3 inhibitors), EGFR ( 9 of 12 inhibitors), JAK3 ( 3 of 3 inhibitors), PKC ( 3 of 4 inhibitors) and Rho kinase ( 2 of 2 inhibitors) were effective in blocking adhesion strength of loaded and non-loaded cells. Two JAK3 and two Rho kinase inhibitors were among the inhibitors that most decreased the $\tau_{50}$. In general, for the library, the inhibitors studied were more effective at reducing adhesion under the static conditions in comparison to loading conditions. Out of a total of 80 inhibitors, 21 inhibited adhesion of statically cultured cancer cells by at least $35 \%$ whereas only four inhibitors were able to reduce adhesion on loaded cells by the same amount. The four inhibitors that reduced the adhesion of loaded cells by this amount included the following: N-Benzoyl Staurosporine, Src Kinase Inhibitor I, PI3K $\gamma$ Inhibitor, and FLT-3 Inhibitor III.

Mechanical strain increases production of angiogenic soluble factors and endothelial cell-like behavior in cancer cells. The gene expression analysis had revealed increases in angiogenesis-related genes in the cancer cells including endothelin-1 (EDN1), follistatin (FST), GATA-binding protein 2 (GATA2), Kruppel like factor 5 (KLF5), Platelet-Derived Growth Factor A (PDGFA), tumor necrosis factor receptor superfamily member 12A (TNFRS12A), and Rho GTPase Activating Protein 22 (ARHGAP22; Supplemental Fig. S1). To test the effect of mechanical loading on the angiogenic properties, we exposed MDA-MB-231 cells to mechanical load for $24 \mathrm{~h}(1 \mathrm{~Hz}$ at $7.5 \%$ strain) and then assayed their angiogenic properties in a tube formation assay. The conditioned media from loaded cells stimulated increased tube formation in endothelial cells (Supplemental Fig. S12A). In addition, cancer cells formed more tubes when seeded on matrigel with mechanical conditioning (Supplemental Fig. S12B), indicative of increased potential for vascular mimicry for the loaded cells $\mathrm{s}^{33}$.

Mechanical strain increases adhesion through Abl1, Yap and Lck-mediated pathways. To understand the mechanotransduction pathways that were key in regulating load-induced increases in cancer cell adhesion under flow, we examined the activation of adhesion related pathways that were implicated by our studies on cancer cell survival and pathways that were indicated from the "hits" from the kinase inhibitor screen. We applied mechanical load to the MDA-MB-231 cells at varying magnitudes for $24 \mathrm{~h}(1 \mathrm{~Hz})$. Immunostaining indicated that there was a decrease in phosphorylated Smad2/3 at mid-level strains (Fig. 5A-C). In addition, at mid-level strains there was also a significant increase in the nuclear cytoplasmic ration of Yap/Taz (Fig. 5A,D). Western blotting to lysates from the loaded cells showed increases in phospho-Yap, phospho-Smad3 and an increase in phosphorylation for phospho-Smad2 (Fig. 5E; Supplemental Fig. S13). In addition, mechanical load led to activation of Lck, Jak1-3, Src, and PKC pathways (Fig. 5F-H; Supplemental Fig. S14-S16). Using inhibitors to Lck, PI3K, Syk and Yap, we demonstrated that many of the pathways were dependent on the activation of Yap (Fig. 5E-H). Yap is key to many of the adhesion-mediated pathways but Lck signaling provides a Yapindependent mechanism for enhancing load-induced adhesion. This pathway is also consistent with our survival studies as Abl1 can be induced by load to increase pro-survival signaling even in the presence of Yap or Jak2 
A

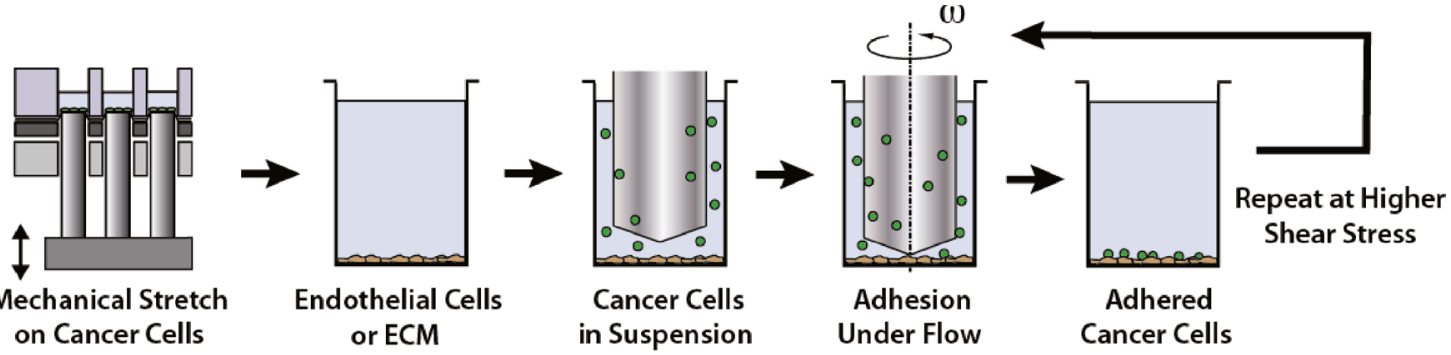

B

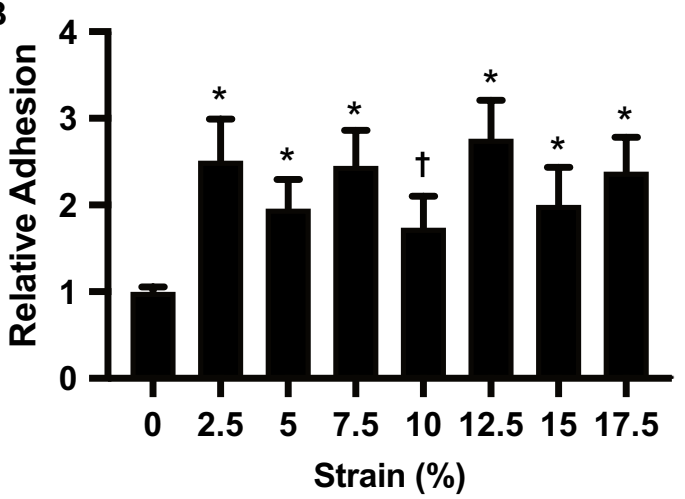

D

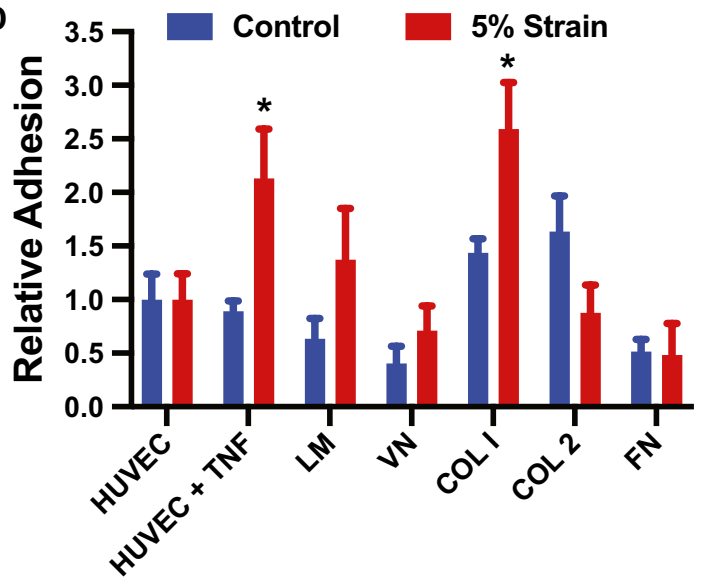

F

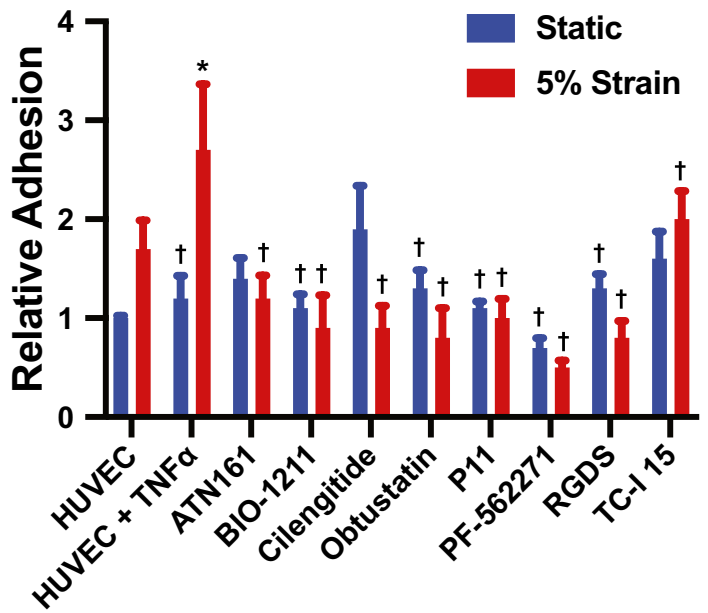

C
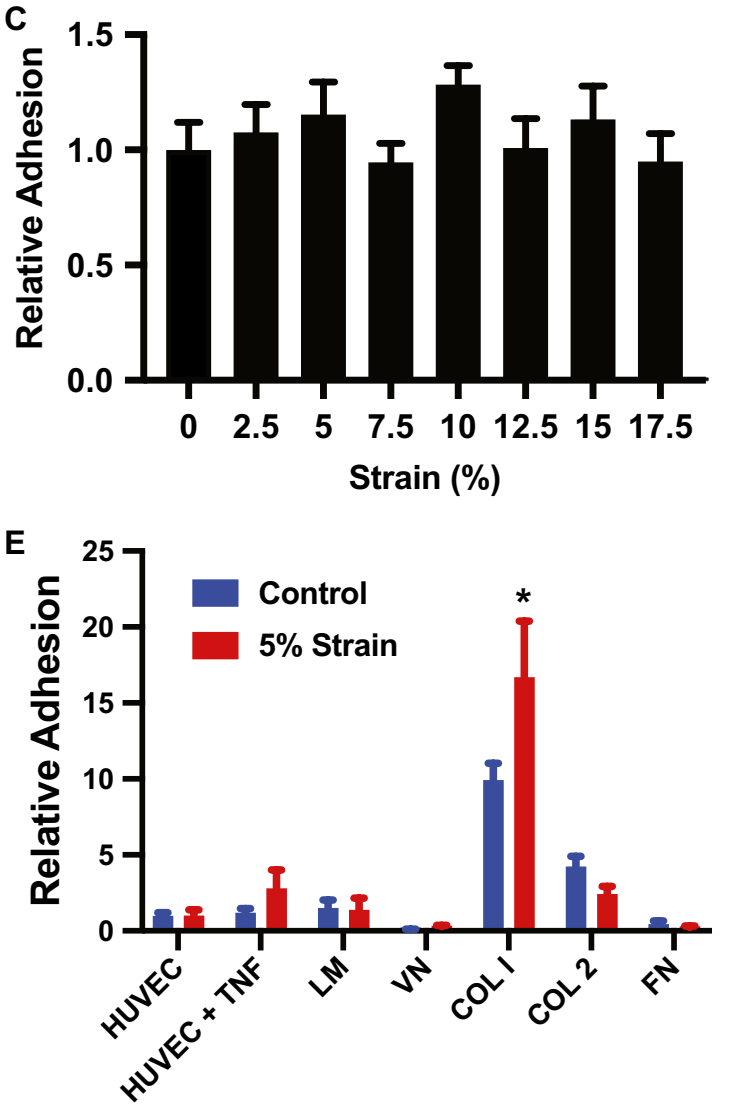

G

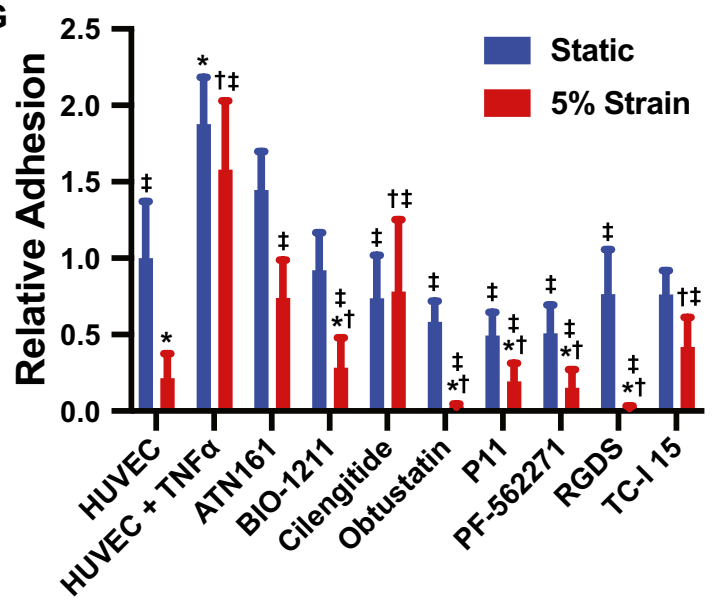


4Figure 3. Mechanical load enhances the adhesion of cancer cells to endothelial cells and collagen I under shear stress. (A) Diagram of the experimental design. The cells were first treated with mechanical load in a high throughput system and then adhesion measured in a high throughput flow device. (B) MDA-MB-231 breast cancer cells were mechanically strained at maximal strain from 0 to $17.5 \%$ at a frequency of 0.1 and $1 \mathrm{~Hz}$ for $24 \mathrm{~h}$. Initial adhesion of strained cells under $0.5 \mathrm{dynes} / \mathrm{cm}^{2}$ shear stress to a TNF- $a$ treated endothelial monolayer was measured relative to the static group. ${ }^{\star} p<0.05$ compared to the static group $(\mathrm{n}=8)$. (C) Relative adhesion of the cells treated with mechanical load after detachment shear stress up to 20 dynes $/ \mathrm{cm}^{2}$. (D) Adhesion of cells to endothelial cells and isolated ECM molecules including laminin (LM), vitronectin (VN), collagen I (COL I), collagen II (COL 2) and fibronectin (FN). ${ }^{*} p<0.05$ versus control group with the same adhesion substrate. (E) Adhesion of cells to endothelial cells and ECM after detachment with shear stresses up 20 dynes $/ \mathrm{cm}^{2}(\mathrm{n}=8)$. ${ }^{*} p<0.05$ versus control group with the same adhesion substrate. (F) Initial adhesion of cells to endothelial cells in the presence of integrin inhibitors. Adhesion is to endothelial cells treated with TNF- $\alpha$ unless otherwise noted. (G) Relative adhesion of cells after detachment up to 20 dynes $/ \mathrm{cm}^{2}(\mathrm{n}=8)$. Adhesion is to endothelial cells treated with TNF- $\alpha$ unless otherwise noted. ${ }^{\star} p<0.05$ versus the HUVEC group. ${ }^{\dagger} p<0.05$ versus the TNF- $\alpha$ treated HUVEC group. ${ }^{\ddagger} p<0.05$ versus the TNF-a treated HUVEC with $5 \%$ strain group.

A

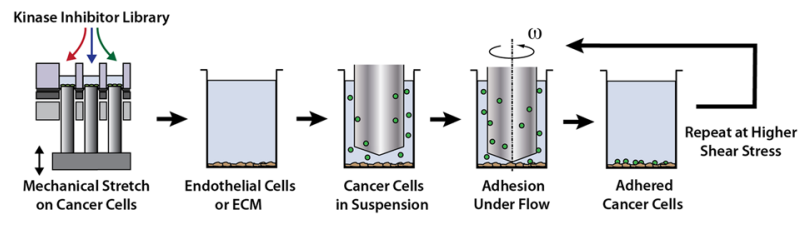

C
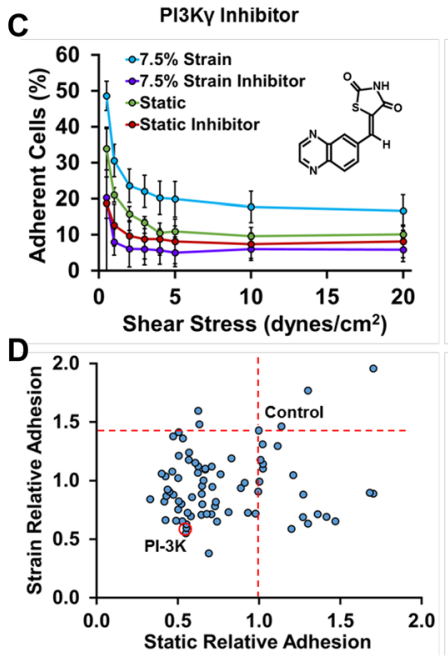

B

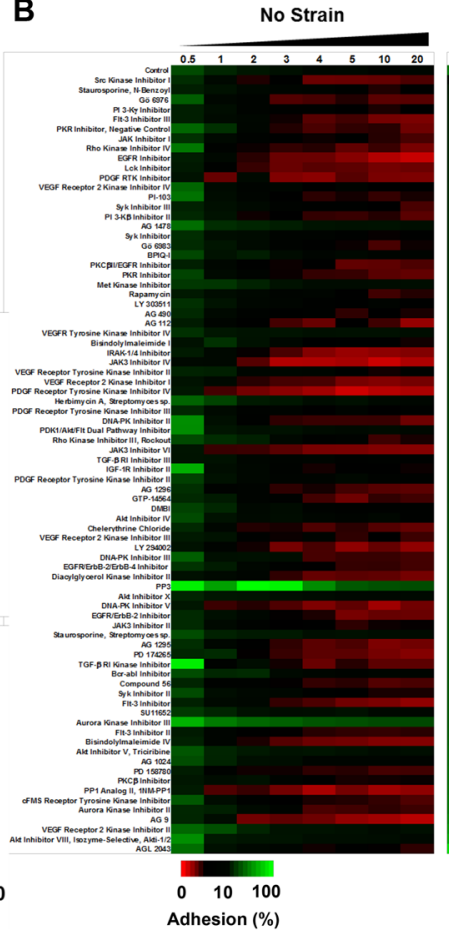

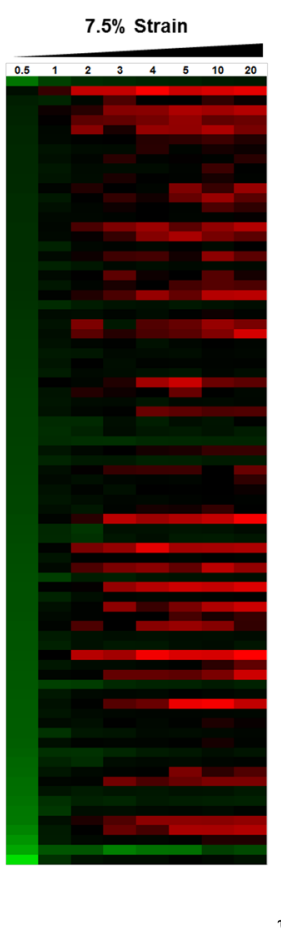

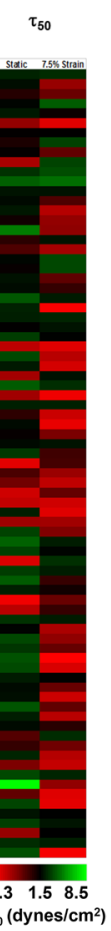

Figure 4. High throughput mechanobiological screens for blocking load-induced enhancement of cancer cells to endothelial cells under shear stress. (A) Diagram of experimental protocol. The cells are loaded in the presence of compounds from a kinase inhibitor library and then the adhesion to inflamed endothelial cells under flow is measured. (B) Heat map of the adhesion and detachment of cancer cells with treatment with kinase inhibitors. (C) Example graphs from the kinase screen for a PI3K inhibitor and Jak3 inhibitor. (D) Results of the kinase inhibitor screen. Compounds in the lower left portion of the graph have reduced initial adhesion or $\tau_{50}$ to endothelial cells. The $\tau_{50}$ is an index of the strength of adhesion. It is the shear stress needed to cause detachment of $50 \%$ of the cells calculated from a curve fit to the detachment of the cells under increases shear stress.

inhibition. We examined the levels of several adhesion receptors that could be involved in enhanced endothelial cell adhesion under mechanical load, however, among these only syndecan-1 (SDC1) was upregulated and a decrease in expression did not correlate with the decreased expression from the inhibitor studies (Fig. 5I; Supplemental Fig. S17). We also examine molecules and signaling related to epithelial-to-mesenchymal transition (EMT). While there were changes with load in some of the molecules, there was not a clear shift to epithelial or mesenchymal phenotype with mechanical loading (Fig. 5J; Supplemental Fig. S18). Combined with our results in the studies on cell survival, these results a signaling cascade in which mechanical load activates multiple pathways that enhance both survival and adhesion (Fig. 6). 
A
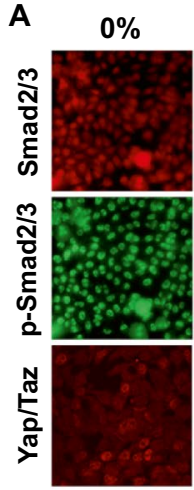

B

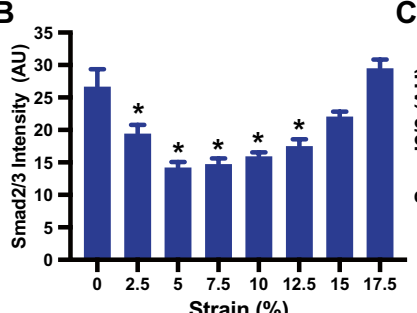

E

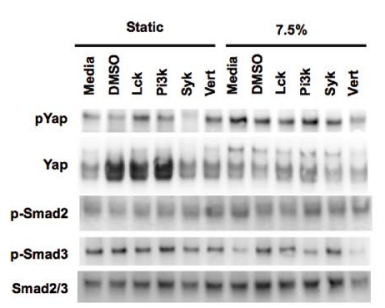

$2.5 \%$
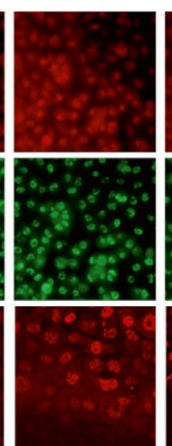

C
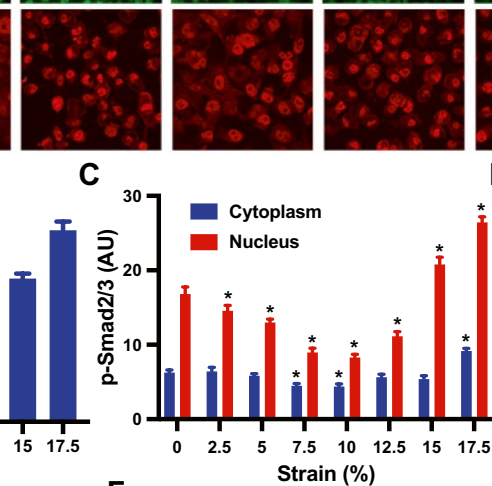

$\mathbf{F}$
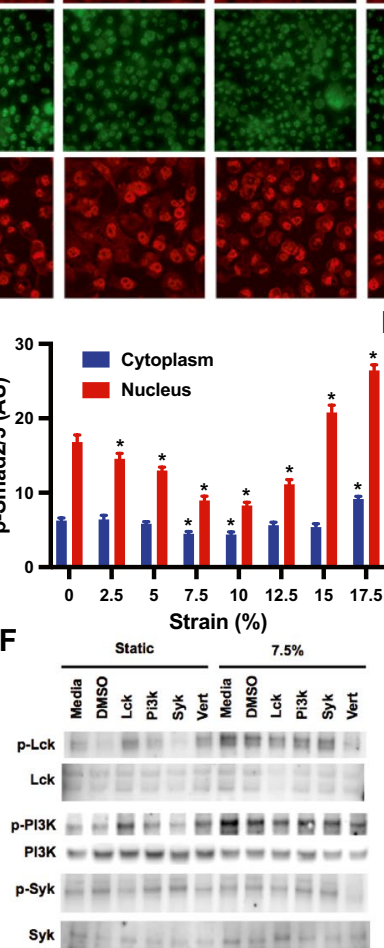
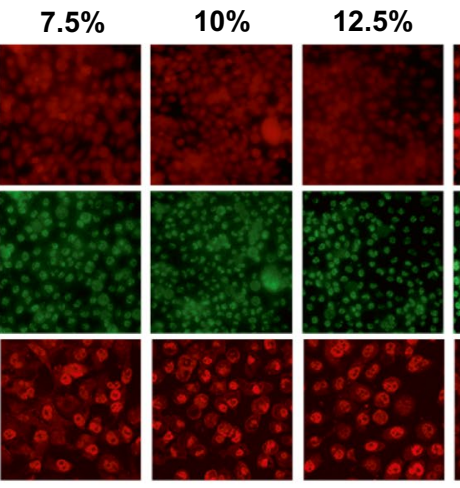

D $\circ$

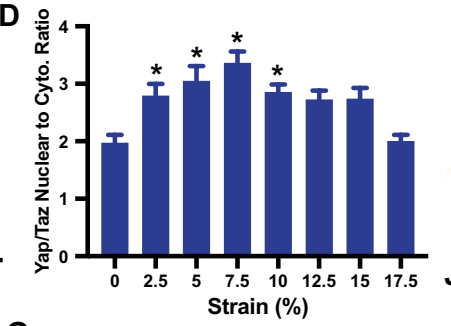

G

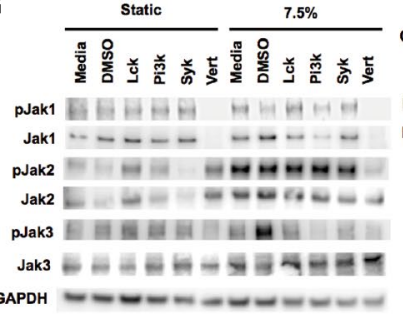

$17.5 \%$
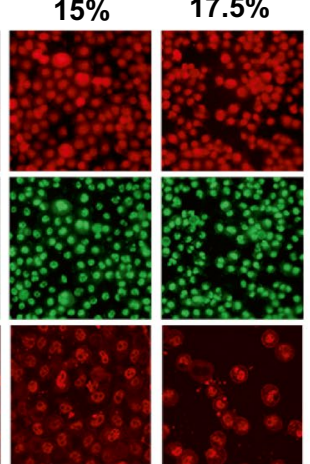

40

\section{(1)}

\section{I}

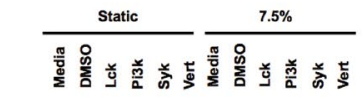

GLG1 [

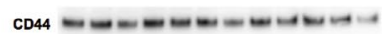

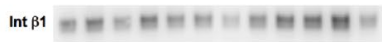
CD11a

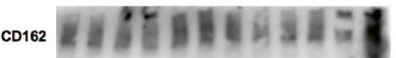

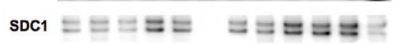

\begin{tabular}{|c|c|c|}
\hline & Static & $7.5 \%$ \\
\hline & 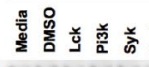 & 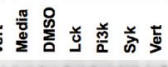 \\
\hline & ーヘールーー & அேールール・ \\
\hline Mucin1 & ーேー・ே & ேேロー・ \\
\hline & - $-2-\cdots$ & $a=$ \\
\hline & 난. & \\
\hline $\begin{array}{l}\text { entin } \\
\text { Zeb1 }\end{array}$ & 6 & - \\
\hline 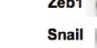 & ext & 1 \\
\hline & & -1 \\
\hline & & \\
\hline
\end{tabular}

Figure 5. Strain differentially activates $S m a d 2 / 3$ and Yap/Taz in breast cancer and epithelial cells. (A) MDA-MB-231 cells were treated with mechanical strain for $24 \mathrm{~h}$ at $1 \mathrm{~Hz}$ with varying magnitudes of maximal strain. Immunostaining for phospho-Smad2/3, Smad2/3 and Yap/Taz was performed. Bar $=100 \mu \mathrm{m} .(\mathbf{B})$ Quantification of total Smad2/3 in the cells $(n=20) .{ }^{\star} p<0.05$ versus static group $(n=20)$. (C) Quantification of phosphorylated $S \mathrm{mad} 2 / 3$ in cells treated mechanical load $(n=20) .{ }^{*} p<0.05$ versus the static group for the same subcellular location. (D) Quantification of nuclear to cytoplasmic Yap/Taz staining $(n=20) .{ }^{*} p<0.05$ versus static group. (E-J) Western blotting for lysates from cells treated with mechanical load for $24 \mathrm{~h}$ and inhibitors Lck, PI3K, Syk and Yap (Vert; verteporfin). Full-length blots/gels are presented in Supplemental Figs. S12-S17.

Mechanical strain induces increased metastasis to the skull, angiogenesis and reduces tumor growth in mouse xenograft models. We next examined whether mechanical conditioning of cancer cells led to altered behavior in in vivo models of tumor growth and metastasis. We mechanically conditioned MDA-MB-231 cells with $7.5 \%$ strain at $1 \mathrm{~Hz}$ for $24 \mathrm{~h}$ and then implanted them in an orthotopic xenograft tumor model in the mammary fat pad of nu/nu mice. We found that there was decreased tumor growth by IVIS imaging for the cells that had been mechanically conditioned in comparison to those grown under static conditions (Fig. 7A,B). The tumor volume measured by calipers was significantly lower in the mechanically conditioned cells in comparison to the controls on day 3; however, there was not a significant difference between static and mechanically loaded cells at other time points (Supplemental Fig. S19A,B). There were also no significant differences in the weight of the tumors on explantation for the comparison between static or mechanically loaded cells at the final time point (Supplemental Fig. S20). Using laser speckle imaging we examined the relative perfusion between the mammary fat pads in the mice. We found significant increases in perfusion in the fat pads of mice with mechanically loaded cancer cells at day 2 and day 8 following implantation (Fig. 7C,D). At later time points, there was no difference in the perfusion between the fat pad with static or mechanically loaded cancer cells (Supplemental Fig. S21). To test whether mechanical conditioning predisposed cancer cells to metastasize, we mechanically conditioned the cells for $24 \mathrm{~h}$ and then injected them through the tail vein in nu/nu or NOD Scid mice. In both the models, we did not observe a significant difference in lung metastases between the mechanically loaded and static culture groups. However, in both models, there was increased tumor colonization of the skull (Fig. 7E-H). When cells were pretreated with a PI3K $\gamma$ inhibitor identified from our high throughput screen we found decreased metastasis to the skull in the mechanically loaded group (Fig. 7G,H). MicroCT analysis of the skull revealed small regions of bone loss in the mice injected with mechanically conditions cells in the occipital and postorbital bones (Supplemental Fig. S22). 


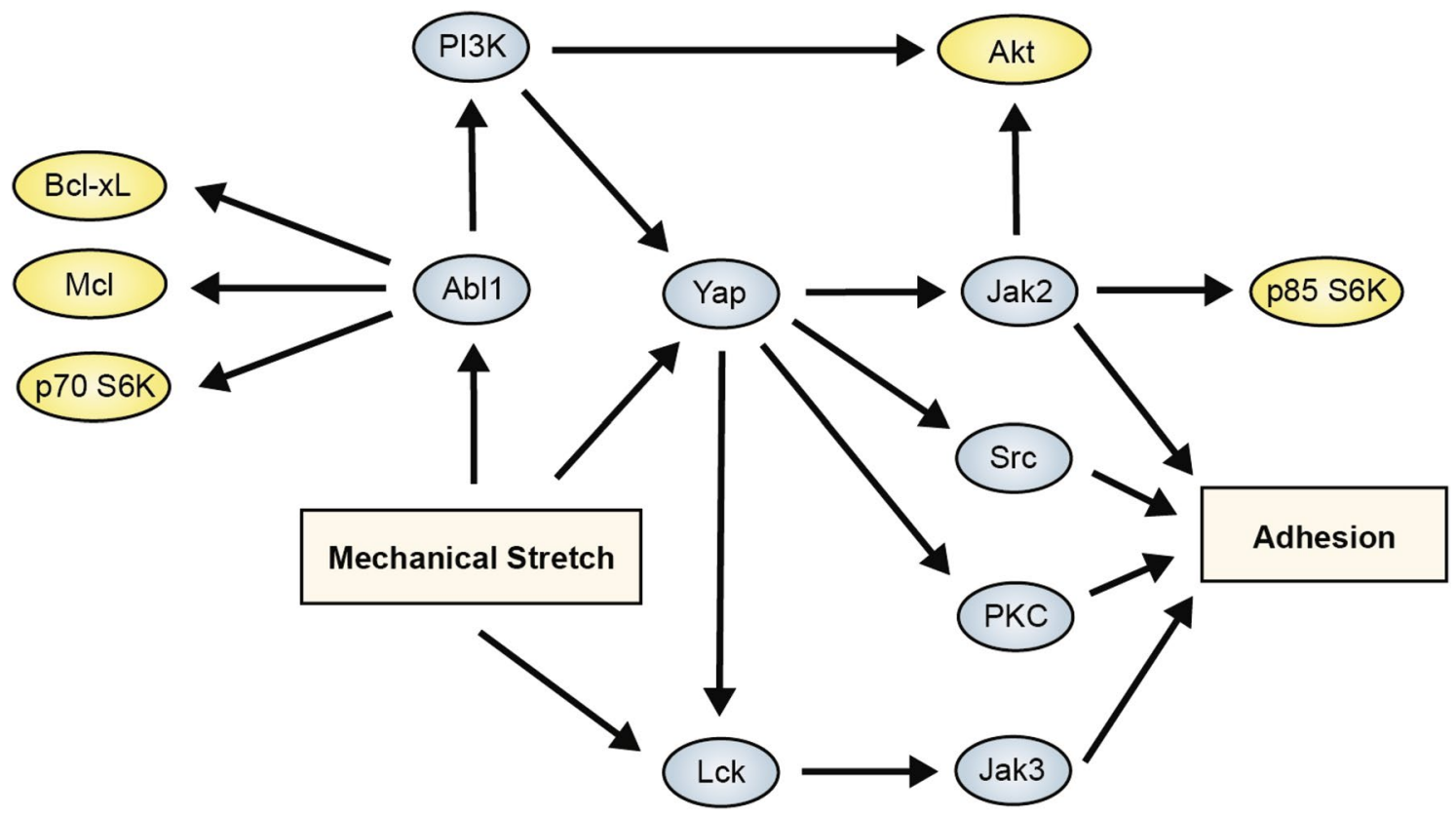

Figure 6. Summary diagram of the mechantransduction mechanisms supported by the studies for the enhancement of survival and adhesion by mechanical load.

\section{Discussion}

While many studies have supported the role of matrix stiffness in regulating cancer biology $y^{4,34-36}$, the role of applied forces on tumor biology is far less well understood. Physical activity has been linked to improved outcomes in breast cancer by many studies. Recent meta-analyses concluded that regular exercise reduces the mortality from breast cancer by $40 \%$ and that physical activity was the most powerful lifestyle-based modifier for breast cancer outcomes ${ }^{37,38}$. While the benefits of exercise in cancer patients would certainly be multifactorial, our study sought to examine whether forces applied to breast cancer cells could directly alter their survival and metastasis. Our findings support that applied cyclic tension induces pro-survival signaling through the Abl1 and Jak2 pathways while reducing proliferation of the cells. This pro-survival signaling enables the tumor cells to survive with level of chemotherapeutics that would otherwise cause cell death. In addition, through a set of mechanobiological screens we identified pathways that underlie load-induced enhancement of cancer cell adhesion to endothelial cells under flow. These pathways included those that were both dependent and independent of Yap signaling.

A major finding of our study is the development of chemoresistance in the mechanically loaded cells through multiple pathways. Notably, in our gene expression analysis several of the aldo-keto reductase family members, related to drug metabolism, were among the most upregulated genes by mechanical load out of the entire genome. In addition to the pro-survival signaling that was increased by mechanical load, upregulation of drug metabolism would further provide a mechanism for chemoresistance. Parallel to our findings, another study found that A549 lung cancer cells when mechanically strained at 20\% maximal strain for 6 days, had reduced proliferation and responsiveness to chemotherapeutic drugs ${ }^{39}$. However, in another study in hepatocellular liver carcinoma cells in which the cells were exposed to shear stress from orbital shaking, there was increased cell death with cisplatin treatment in combination with shear stress ${ }^{40}$. In MDA-MB-231 cells, 15 min of vibrational stresses per day also reduced proliferation ${ }^{13}$. While compressive stress was found to enhance invasion in several cancer cell lines including the MDA-MB-231 cell line ${ }^{10}$. In addition, compressive forces can suppress proliferation and induce apoptosis in cancer cells ${ }^{14}$. Our in vivo study did not show differences in tumor growth under doxorubicin treatment. However, our study had the limitation that the loading was only applied prior to implantation and thus this would suggest that effects of load are reduced over time. This concept is further supported by our finding that angiogenesis was increased in loaded cells at early time points but not for later time points. From these studies, one could infer the timeline of the effects of load last around one week. A recent study found that mice that performed stretching exercises after orthotopic implantation of breast cancer cells also had reduced tumor growth ${ }^{41}$. These findings are consistent with our results and support that breast cancer growth can be reduced by mechanical stretch.

The overexpression of Yap is associated with tumor progression and worsening patient prognosis in many types of cancer ${ }^{42-47}$. However, in breast cancer the role of Yap is complex, with studies supporting both tumor suppressor and tumor promoting activities ${ }^{48}$. Specifically, decreased expression of Yap is associated with tumor progression and reduced patient survival with breast cancer in some studies ${ }^{49,50}$, Yap knockdown leading to enhanced invasiveness and tumor growth in mice $\mathrm{e}^{51}$ and support a role for Yap as a tumor suppressor ${ }^{52}$. In contrast, other studies have shown that nuclear Yap drives breast cancer proliferation and survival, maintains stemness and promotes metastasis ${ }^{53-55}$. In addition, nuclear Yap correlated with tumor progression and decreased survival for patient with breast cancer in some studies ${ }^{56-58}$. In our study, we found that Yap nuclear localization 
A
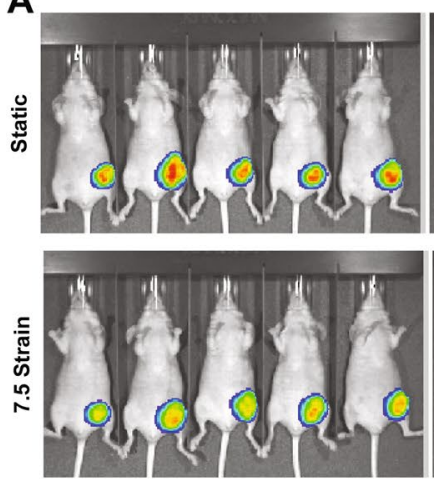

C

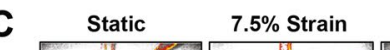

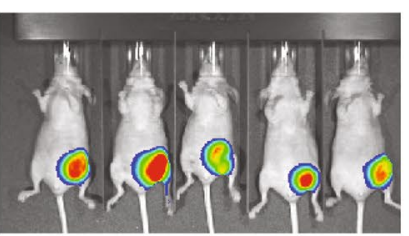

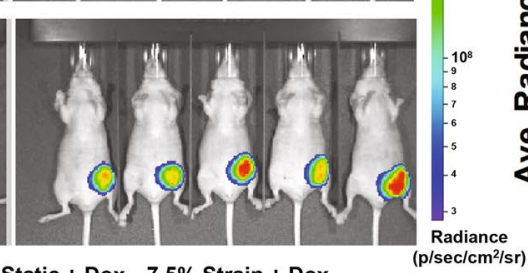

Static + Dox $7.5 \%$ Strain + Dox
B

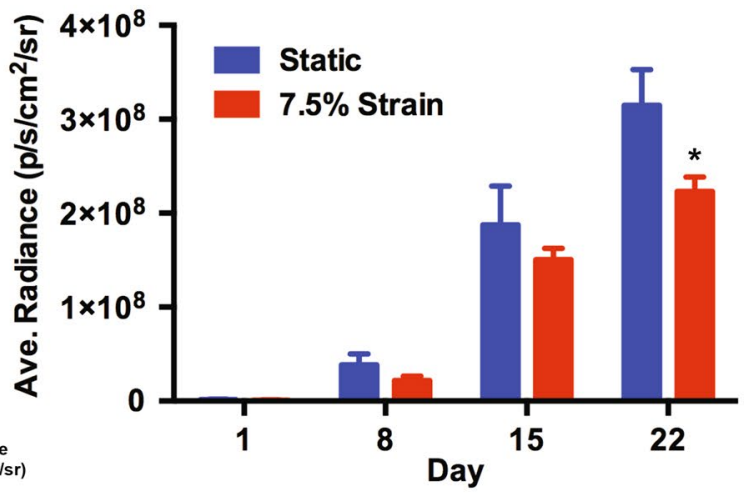

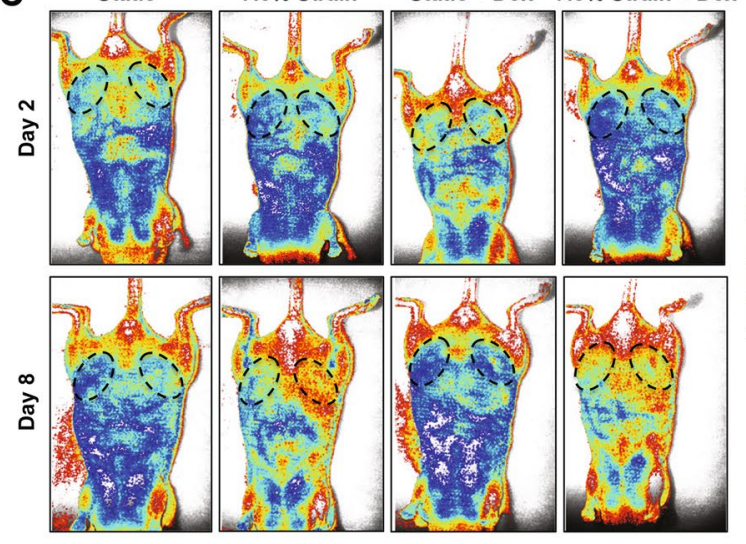

E

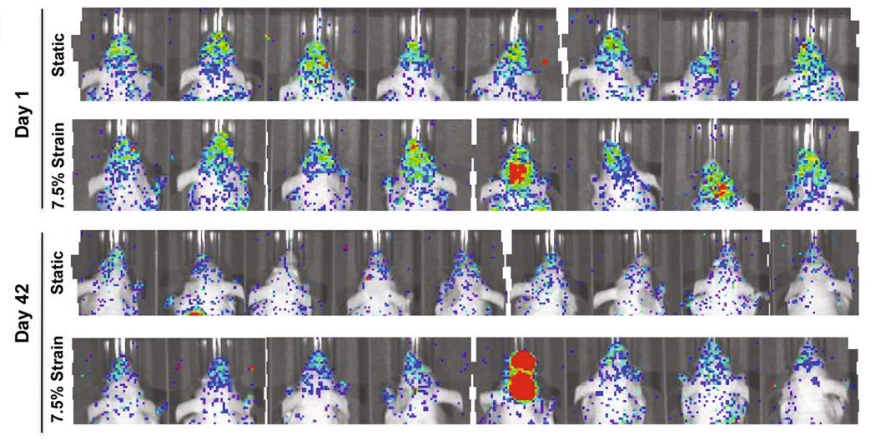

G

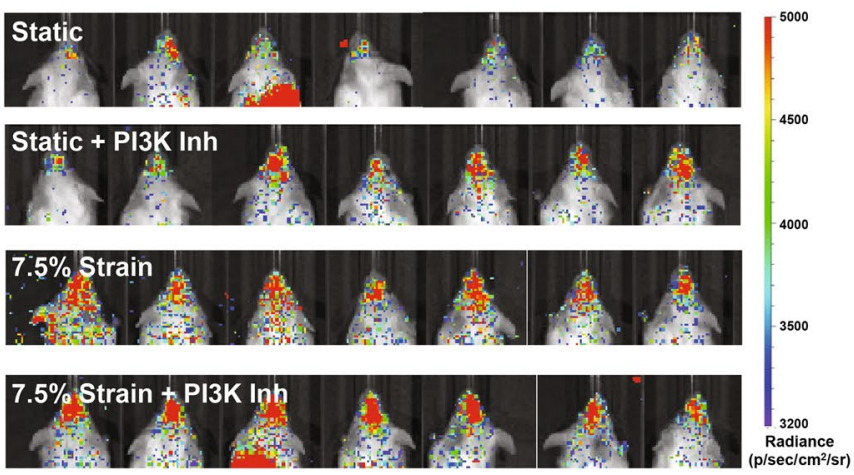

D
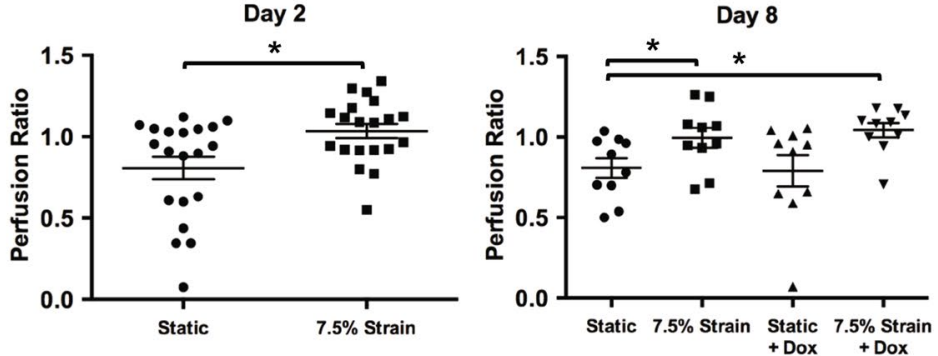

Figure 7. Mechanical loading decreases tumor growth and increases metastasis to the skull in immune compromised mice. (A) Luciferase expressing MDA-MB-231 cells were grown under static or mechanically loaded conditions for $24 \mathrm{~h}$ and then implanted into the mammary fat pad of nu/nu mice. Radiance of mice with orthotopic tumor implantation at 22 days. (B) Quantification of the radiance in the mammary fat pad. ${ }^{*} p<0.05$ versus static group $(n=10)$. (C) Laser speckle imaging of mice with orthotopic implantation of MDA-MB-231 cells after mechanical conditioning. (D) Ratio of perfusion of the mammary fat pad with tumor implantation to contralateral control fat pad. ${ }^{*} p<0.05$ between indicated groups $(n=10)$. (E) Images of luminescence as measured by IVIS for nu/nu given an intravenous injection of MDA-MB-231 cells. The cells were cultured under static or $7.5 \%$ strain for $24 \mathrm{~h}$ prior to injection. (F) Quantification of luminescence in the head of the mice given an intravenous injection of MDA-MB-231 cells at day 42 following injection. ${ }^{*} p<0.05$ versus static group $(n=8-9)$. (G) Luminescence in the heads of NOD Scid mice 42 days after tail vein injection of MDA-MB-231 cells. (H) Quantification of the luminescence in the head of the mice after 42 days. ${ }^{*} p<0.05$ versus indicated group $(n=7-8)$. 
was increased with mid-range mechanical loads with accompanying decrease in Smad2/3 signaling and an increase in cell adhesion. Our results, in terms of Yap signaling, showed a mix between the two sides of Yap signaling present in previous studies with exposure of the cells to mechanical strain. We found that resistance to cell death with mechanical load and promotion of metastasis to the skull. In addition, we demonstrate some tumor suppressor-like activity in slowing cell growth.

Our studies found enhanced metastasis to the skull of mice injected with mechanically loaded cells. Yap/Taz pathway activation has been observed in high-grade breast cancer metastatic cancer in comparison to non-metastatic cancer ${ }^{59}$. Taz is also required for metastasis in breast cancer stem cells ${ }^{60}$. Activation of Yap pathway target genes induces bone metastasis in breast cancer through signaling pathways involving ROR1, HER3 and lncRNA MAYA $^{61}$. In our studies, we found Yap-dependent activation of Src, PKC and Jak2 was partially responsible for load induced increases in adhesion. However, there appeared to be a separate mechanism acting through Lck and Jak3 that also increased adhesion following loading. Thus, these findings are consistent with previous work suggesting Yap activation increases bone metastasis but also suggests that targeting Yap would not be sufficient to completely block this effect. Our screen for metastasis inhibitors identified inhibitors to several pathways that reduced the adhesion of cancer cells with and without mechanical preconditioning. These included inhibitors to FLT-3, PI-3 K, JAK3, EGFR and VEGFR. Consistent with our findings here, our previous study using the high throughput shear stress device also identified FLT-3 inhibitors to be effective in blocking cancer cell adhesion to endothelial cells under shear stress ${ }^{16}$. The PI3K inhibitor reduced metastasis to the skull in immune compromised mice for the load conditioned cells, suggesting the strategy of screening for inhibitors of cancer cell to endothelial cell adhesion could be a means to identify therapeutics that protect against metastatic spread of cancer but that multiple pathway targeting may be needed.

Overall, our studies support the concept that microenvironmental mechanical stresses can regulate many aspects of breast cancer biology. The mechanical loading environment of tumors in the body is highly variable and there is potential that tumor cells that are in locations with specific mechanical forces may be predisposed to survive during chemotherapy, to metastasize or induce the development of vasculature. Thus, there is a need to consider the effects of mechanical forces on tumor behavior when designing and testing therapeutics for cancer or developing accurate models of tumor growth.

Received: 9 March 2020; Accepted: 22 April 2021

Published online: 10 May 2021

\section{References}

1. Jain, R. K., Martin, J. D. \& Stylianopoulos, T. The Role of Mechanical Forces in Tumor Growth and Therapy. In Annual Review of Biomedical Engineering Vol. 16 (ed. Yarmush, M. L.) 321-346 (Palo Alto, 2014).

2. Yu, H. M., Mouw, J. K. \& Weaver, V. M. Forcing form and function: Biomechanical regulation of tumor evolution. Trends Cell Biol. (Review) 21, 47-56 (2011).

3. Butcher, D. T., Alliston, T. \& Weaver, V. M. A tense situation: Forcing tumour progression. Nat. Rev. Cancer 9, 108-122 (2009).

4. Levental, K. R. et al. Matrix crosslinking forces tumor progression by enhancing integrin signaling. Cell 139, 891-906 (2009).

5. Tilghman, R. W. et al. Matrix rigidity regulates cancer cell growth and cellular phenotype. PLoS ONE 5, e12905 (2010).

6. Schedin, P. \& Keely, P. J. Mammary gland ECM remodeling, stiffness, and mechanosignaling in normal development and tumor progression. Cold Spring Harb. Perspect. Biol. 3, a003228 (2011).

7. Nia, H. T. et al. Solid stress and elastic energy as measures of tumour mechanopathology. Nat. Biomed. Eng. 1, 1 (2016).

8. Stylianopoulos, T. et al. Causes, consequences, and remedies for growth-induced solid stress in murine and human tumors. Proc. Natl. Acad. Sci. USA 109, 15101-15108 (2012).

9. Nia, H. T. et al. Quantifying solid stress and elastic energy from excised or in situ tumors. Nat. Protoc. 13, 1091-1105 (2018).

10. Tse, J. M. et al. Mechanical compression drives cancer cells toward invasive phenotype. Proc. Natl. Acad. Sci. USA 109, $911-916$ (2012).

11. Holle, A. W., Young, J. L. \& Spatz, J. P. In vitro cancer cell-ECM interactions inform in vivo cancer treatment. Adv. Drug Deliv. Rev. 97, 270-279 (2016).

12. Gefen, A. \& Dilmoney, B. Mechanics of the normal woman's breast. Technol. Health Care 15, 259-271 (2007).

13. Olcum, M. \& Ozcivici, E. Daily application of low magnitude mechanical stimulus inhibits the growth of MDA-MB-231 breast cancer cells in vitro. Cancer Cell Int. 14, 102 (2014).

14. Cheng, G., Tse, J., Jain, R. K. \& Munn, L. L. Micro-environmental mechanical stress controls tumor spheroid size and morphology by suppressing proliferation and inducing apoptosis in cancer cells. PLoS ONE 4, e4632 (2009).

15. Spencer, A. \& Baker, A. B. High Throughput Label Free Measurement of Cancer Cell Adhesion Kinetics Under Hemodynamic Flow. Sci Rep 6, 19854 (2016).

16. Spencer, A. et al. A high-throughput mechanofluidic screening platform for investigating tumor cell adhesion during metastasis. Lab Chip 16, 142-152 (2016).

17. Spruell, C. \& Baker, A. B. Analysis of a high-throughput cone-and-plate apparatus for the application of defined spatiotemporal flow to cultured cells. Biotechnol Bioeng 110, 1782-1793 (2013).

18. Lee, J. et al. A high throughput screening system for studying the effects of applied mechanical forces on reprogramming factor expression. Sci. Rep. 10, 15469 (2020).

19. Lee, J. \& Baker, A. B. Computational analysis of fluid flow within a device for applying biaxial strain to cultured cells. J. Biomech. Eng. 137, 051006 (2015).

20. Lee, J. et al. Mechanobiological conditioning enhances mesenchymal stem cell-induced vascular regeneration. Nat. Biom. Eng. 2020, 1 (2020).

21. Lee, J., Wong, M., Smith, Q. \& Baker, A. B. A novel system for studying mechanical strain waveform-dependent responses in vascular smooth muscle cells. Lab Chip 13, 4573-4582 (2013).

22. Team RC. R: A Language and Environment for Statistical Computing (R Foundation for Statistical Computing, 2019).

23. Koch, C. M. et al. A Beginner's guide to analysis of RNA sequencing data. Am. J. Respir. Cell Mol. Biol. 59, 145-157 (2018).

24. Das, S. et al. Syndecan-4 enhances therapeutic angiogenesis after hind limb ischemia in mice with type 2 diabetes. Adv. Healthc. Mater. 5, 1008-1013 (2016).

25. Monteforte, A. J. et al. Glypican-1 nanoliposomes for potentiating growth factor activity in therapeutic angiogenesis. Biomaterials 94, 45-56 (2016). 
26. Greuber, E. K., Smith-Pearson, P., Wang, J. \& Pendergast, A. M. Role of ABL family kinases in cancer: From leukaemia to solid tumours. Nat. Rev. Cancer 13, 559-571 (2013).

27. Allington, T. M., Galliher-Beckley, A. J. \& Schiemann, W. P. Activated Abl kinase inhibits oncogenic transforming growth factorbeta signaling and tumorigenesis in mammary tumors. FASEB J. 23, 4231-4243 (2009).

28. Li, B. et al. c-Abl regulates YAPY357 phosphorylation to activate endothelial atherogenic responses to disturbed flow. J. Clin. Invest. 129, 1167-1179 (2019)

29. Lewis, J. M. \& Schwartz, M. A. Integrins regulate the association and phosphorylation of paxillin by c-Abl. J. Biol. Chem. 273, 14225-14230 (1998).

30. Bendas, G. \& Borsig, L. Cancer cell adhesion and metastasis: Selectins, integrins, and the inhibitory potential of heparins. Int. J. Cell Biol. 2012, 676731 (2012).

31. Kobayashi, K., Matsumoto, S., Morishima, T., Kawabe, T. \& Okamoto, T. Cimetidine inhibits cancer cell adhesion to endothelial cells and prevents metastasis by blocking E-selectin expression. Cancer Res. 60, 3978-3984 (2000).

32. Spencer, A. et al. A high-throughput mechanofluidic screening platform for investigating tumor cell adhesion during metastasis. Lab Chip 16, 142-152 (2015).

33. Angara, K., Borin, T. F. \& Arbab, A. S. Vascular mimicry: A novel neovascularization mechanism driving anti-angiogenic therapy (AAT) resistance in glioblastoma. Transl. Oncol. 10, 650-660 (2017).

34. Reid, S. E. et al. Tumor matrix stiffness promotes metastatic cancer cell interaction with the endothelium. EMBO J. 36, 2373-2389 (2017).

35. Pickup, M. W., Mouw, J. K. \& Weaver, V. M. The extracellular matrix modulates the hallmarks of cancer. EMBO Rep. 15, 1243-1253 (2014).

36. Paszek, M. J. et al. Tensional homeostasis and the malignant phenotype. Cancer Cell 8, 241-254 (2005).

37. Hamer, J. \& Warner, E. Lifestyle modifications for patients with breast cancer to improve prognosis and optimize overall health. CMAJ 189, E268-E274 (2017).

38. Lahart, I. M., Metsios, G. S., Nevill, A. M. \& Carmichael, A. R. Physical activity, risk of death and recurrence in breast cancer survivors: A systematic review and meta-analysis of epidemiological studies. Acta Oncol. 54, 635-654 (2015).

39. Hendricks, P., Diaz, F. J., Schmitt, S., Sitta Sittampalam, G. \& Nirmalanandhan, V. S. Effects of respiratory mechanical forces on the pharmacological response of lung cancer cells to chemotherapeutic agents. Fundam. Clin. Pharmacol. 26, 632-643 (2012).

40. Ziko, L. et al. Mechanical stress promotes cisplatin-induced hepatocellular carcinoma cell death. Biomed. Res. Int. 2015, 430569 (2015).

41. Berrueta, L. et al. Stretching reduces tumor growth in a mouse breast cancer model. Sci. Rep. 8, 7864 (2018).

42. Zender, L. et al. Identification and validation of oncogenes in liver cancer using an integrative oncogenomic approach. Cell 125, 1253-1267 (2006).

43. Xu, M. Z. et al. Yes-associated protein is an independent prognostic marker in hepatocellular carcinoma. Cancer 115, 4576-4585 (2009).

44. Wang, Y. et al. Overexpression of yes-associated protein contributes to progression and poor prognosis of non-small-cell lung cancer. Cancer Sci. 101, 1279-1285 (2010).

45. Song, M., Cheong, J. H., Kim, H., Noh, S. H. \& Kim, H. Nuclear expression of Yes-associated protein 1 correlates with poor prognosis in intestinal type gastric cancer. Anticancer Res. 32, 3827-3834 (2012).

46. Su, L. L. et al. Expression of Yes-associated protein in non-small cell lung cancer and its relationship with clinical pathological factors. Chin. Med. J. (Engl.) 125, 4003-4008 (2012).

47. Liu, T. et al. Clinical significance of yes-associated protein overexpression in cervical carcinoma: The differential effects based on histotypes. Int J Gynecol Cancer 23, 735-742 (2013).

48. Maugeri-Sacca, M. et al. The Hippo transducers TAZ and YAP in breast cancer: Oncogenic activities and clinical implications. Expert Rev. Mol. Med. 17, e14 (2015).

49. Tufail, R., Jorda, M., Zhao, W., Reis, I. \& Nawaz, Z. Loss of Yes-associated protein (YAP) expression is associated with estrogen and progesterone receptors negativity in invasive breast carcinomas. Breast Cancer Res. Treat. 131, 743-750 (2012).

50. Lehn, S. et al. Decreased expression of Yes-associated protein is associated with outcome in the luminal A breast cancer subgroup and with an impaired tamoxifen response. BMC Cancer 14, 119 (2014).

51. Yuan, M. et al. Yes-associated protein (YAP) functions as a tumor suppressor in breast. Cell Death Differ. 15, 1752-1759 (2008).

52. Matallanas, D. et al. RASSF1A elicits apoptosis through an MST2 pathway directing proapoptotic transcription by the p73 tumor suppressor protein. Mol. Cell 27, 962-975 (2007).

53. Yu, S. J. et al. MicroRNA-200a promotes anoikis resistance and metastasis by targeting YAP1 in human breast cancer. Clin. Cancer Res. 19, 1389-1399 (2013).

54. Diepenbruck, M. et al. Tead2 expression levels control the subcellular distribution of Yap and Taz, zyxin expression and epithelialmesenchymal transition. J. Cell Sci. 127, 1523-1536 (2014).

55. Sethunath, V. et al. Targeting the mevalonate pathway to overcome acquired anti-HER2 treatment resistance in breast cancer. Mol. Cancer Res. 17, 2318-2330 (2019).

56. Chen, Q. et al. A temporal requirement for Hippo signaling in mammary gland differentiation, growth, and tumorigenesis. Genes Dev. 28, 432-437 (2014).

57. Pegoraro, S. et al. A novel HMGA1-CCNE2-YAP axis regulates breast cancer aggressiveness. Oncotarget 6, 19087-19101 (2015).

58. Sudol, M. Yes-associated protein (YAP65) is a proline-rich phosphoprotein that binds to the SH3 domain of the Yes proto-oncogene product. Oncogene 9, 2145-2152 (1994).

59. Cordenonsi, M. et al. The Hippo transducer TAZ confers cancer stem cell-related traits on breast cancer cells. Cell 147, 759-772 (2011).

60. Bartucci, M. et al. TAZ is required for metastatic activity and chemoresistance of breast cancer stem cells. Oncogene 34, 681-690 (2015).

61. Li, C. et al. A ROR1-HER3-IncRNA signalling axis modulates the Hippo-YAP pathway to regulate bone metastasis. Nat. Cell Biol. 19, 106-119 (2017).

\section{Acknowledgements}

The authors gratefully acknowledge funding through the National Institutes of Health (1R21EB023551-01; 1R21EB024147-01A1; 1R01HL141761-01) to ABB. The authors also acknowledge support through a graduate fellowship from the NSF (DGE-1610403) to A.S.

\section{Author contributions}

A.S., A.D.S. and A.B.B. analyzed the data and wrote the manuscript. A.S., A.D.S., D.C., J.L., D.C., N.P.P., H.W.L., A.P.V., W.J.R., S.D., A.A., and R.S. performed experiments and processed the data. All authors reviewed the manuscript. 


\section{Competing interests}

The authors declare no competing interests.

\section{Additional information}

Supplementary information The online version contains supplementary material available at https://doi.org/ 10.1038/s41598-021-89288-z.

Correspondence and requests for materials should be addressed to A.B.B.

Reprints and permissions information is available at www.nature.com/reprints.

Publisher's note Springer Nature remains neutral with regard to jurisdictional claims in published maps and institutional affiliations.

(c) (1) Open Access This article is licensed under a Creative Commons Attribution 4.0 International License, which permits use, sharing, adaptation, distribution and reproduction in any medium or format, as long as you give appropriate credit to the original author(s) and the source, provide a link to the Creative Commons licence, and indicate if changes were made. The images or other third party material in this article are included in the article's Creative Commons licence, unless indicated otherwise in a credit line to the material. If material is not included in the article's Creative Commons licence and your intended use is not permitted by statutory regulation or exceeds the permitted use, you will need to obtain permission directly from the copyright holder. To view a copy of this licence, visit http://creativecommons.org/licenses/by/4.0/.

(C) The Author(s) 2021 